University of Rhode Island

DigitalCommons@URI

Open Access Dissertations

1999

\title{
Attatchment Classification Among 18 Month Old Children of Adolescent Mothers
}

Lynne M. Andreozzi

University of Rhode Island

Follow this and additional works at: https://digitalcommons.uri.edu/oa_diss

\section{Recommended Citation}

Andreozzi, Lynne M., "Attatchment Classification Among 18 Month Old Children of Adolescent Mothers" (1999). Open Access Dissertations. Paper 775.

https://digitalcommons.uri.edu/oa_diss/775

This Dissertation is brought to you for free and open access by DigitalCommons@URI. It has been accepted for inclusion in Open Access Dissertations by an authorized administrator of DigitalCommons@URI. For more information, please contact digitalcommons-group@uri.edu. 
ATTACHMENT CLASSIFICATIONS AMONG 18-MONTH-OLD CHILDREN OF ADOLESCENT MOTHERS

BY

LYNNE ANDREOZZI

A DISSERTATION SUBMITTED IN PARTIAL FULFILLMENT OF THE

REQUIREMENTS FOR THE DEGREE OF

DOCTOR OF PHILOSOPHY

IN

PSYCHOLOGY

UNIVERSITY OF RHODE ISLAND

1999 


\title{
DOCTOR OF PHILOSOPHY DISSERTATION
}

\author{
$\mathrm{OF}$
}

\section{LYNNE ANDREOZZI}

\section{APPROVED:}

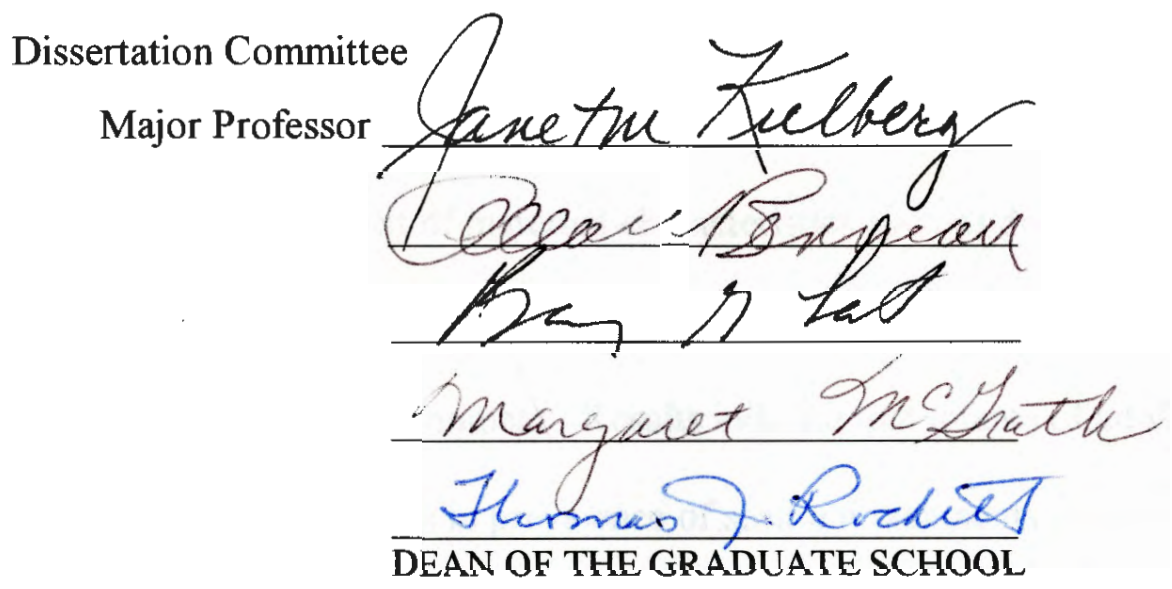

UNIVERSITY OF RHODE ISLAND 


\section{Abstract}

This investigation was conducted to examine the nature of the attachment relationship among children of adolescent mothers using a standard measure known as the Strange Situation procedure. This project compared the attachment relationships of children of adolescent mothers with children of older, non-adolescent adult mothers. Given the paucity of research on attachment among infants of adolescent mothers, the rationale for conducting this study was to supplement an existing weak literature base. The major prediction of this study was that there would be significantly more insecurity among 18-month-old infants of adolescent mothers. The study further attempted to examine this relationship in the context of maternal characteristics such as depression, selfesteem, parenting stress, child abuse potential, psychological distress, perception of infant behavior, as well as the caregiving environment. Results indicate that infants of adolescent mothers may resemble normative groups in prevalence of secure attachments to their mothers. However, the mothers in the adolescent group reported lower amounts of selfesteem, more parenting stress, more child abuse potential, and provided a lower quality of the home environment than the mothers in the non-adolescent group. These mothers also rated their infants as having a higher activity level than infants born to older mothers. Results are discussed in terms of implications for future research and interventions. 


\section{Acknowledgments}

There are several people that I would like to acknowledge for their support, encouragement, and understanding during my graduate career. Most of them will never truly know the impact that they have had upon my life. I would like to extend my sincerest thanks and gratitude to my major professor, Dr. Janet Kulberg, for her continued support, guidance, and interest throughout this process and through my graduate career. Her knowledge and guidance have been invaluable to me. I would also like to thank the members of my committee for their contributions to this project and my professional career. I thank Dr. Barry Lester, for his thoughtful questions, support, and the opportunity to utilize this data. He has been a mentor and a constant source of support for me. I thank Dr. Al Berman for his time and encouragement; Dr. Margaret McGrath for her insight and support; Dr. Ronald Seifer for his expertise and insight into this project; and Dr. David Byrd for his time and support. I would also like to thank Dr. Patricia Flanagan for advising me on this topic and for the opportunity to use this data. I also thank my friend and colleague, Susan Brunner, for her help with this project

Finally, I would like to thank my family and friends for their love and support, without them, this may not have been possible. First, I thank my husband, Kevin Fontaine, for his unconditional love and support through this process. His understanding and patience helped me immensely. Without him, I may not have seen this project to fruition. I would like to thank my parents, Joseph and Rosemary Andreozzi, for their encouragement and love. They have always been a source of encouragement and support for all of my endeavors. I truly appreciate and treasure their love. And finally, my brother, Mark Andreozzi, for always believing in me. I admire him for being able to do what I was always afraid of doing. I would also like to thank the rest of my family and friends who have supported me with their understanding, encouragement, love, and laughter. 


\section{Table of Contents}

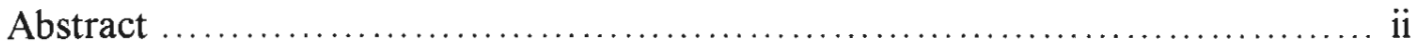

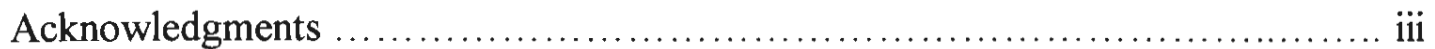

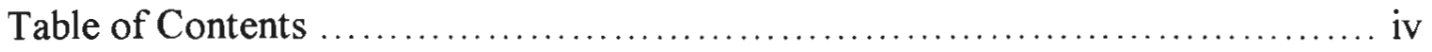

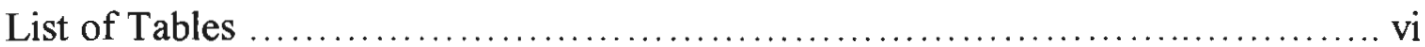

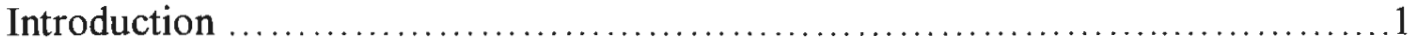

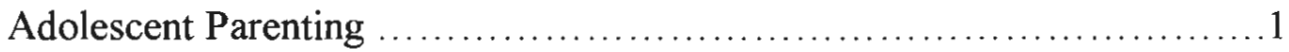

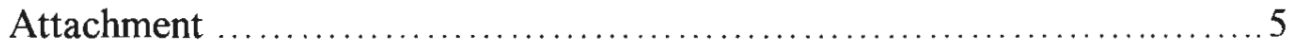

Maternal Predictors of Attachment .................................. 8

Infant Predictors of Attachment .................................... 10

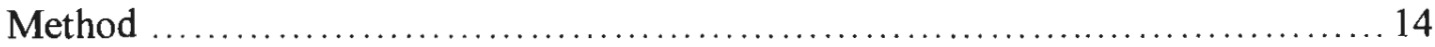

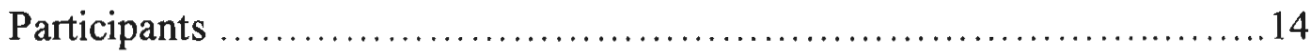

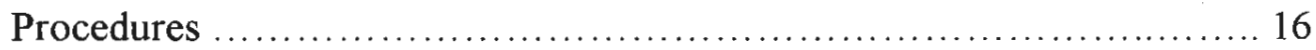

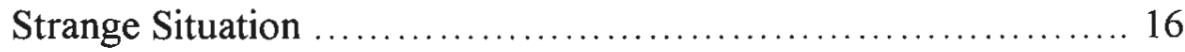

Maternal Characteristics ..................................... 19

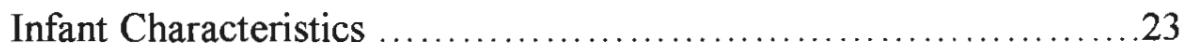

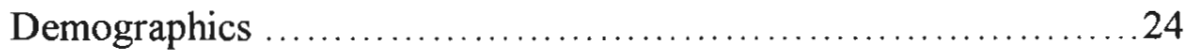

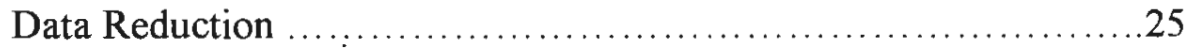

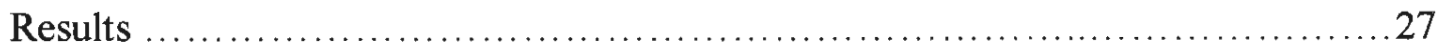

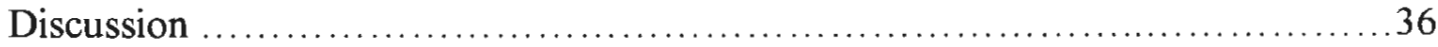

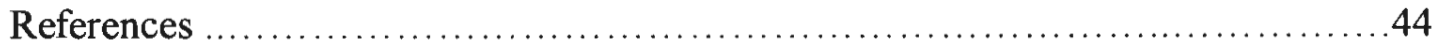

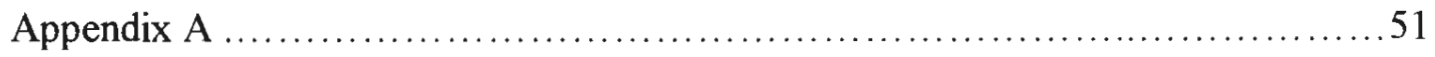

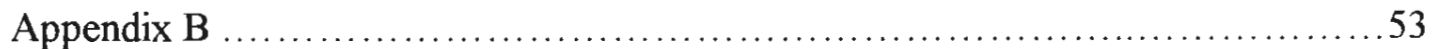

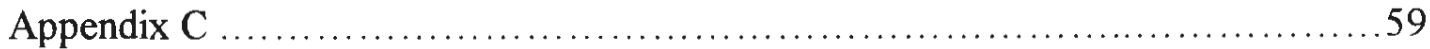

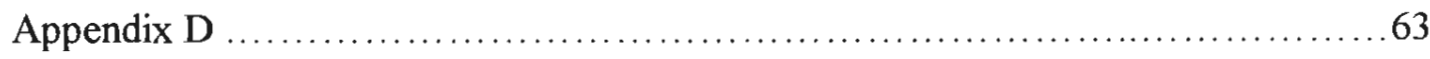




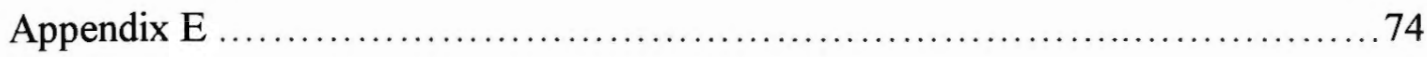

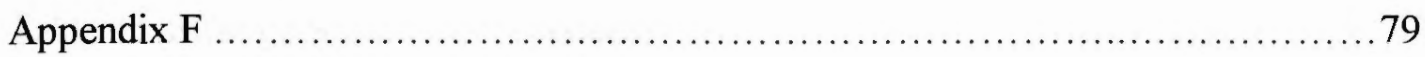

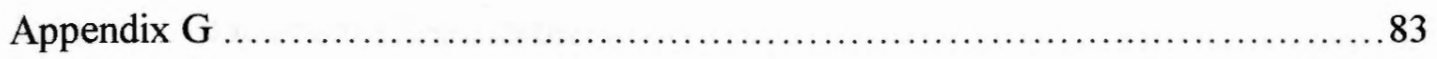

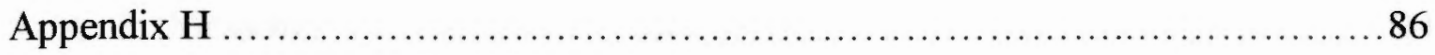

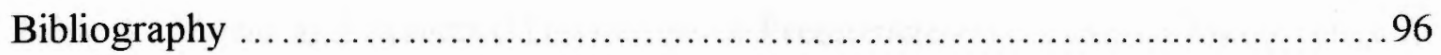




\section{List of Tables}

Table 1: Strange Situation Procedure

Table 2: Attachment Classifications

Table 3: Measures

Table 4: Means and Standard Deviations or Frequencies and Tests of Significance 29 for Maternal Demographic Characteristics of Sample by Maternal Age Group

Table 5: Means and Standard Deviations or Frequencies and Tests of Significance 30 for Infant Demographic Characteristics of Sample by Maternal Age Group

Table 6: Number and (Percent) of Each Attachment Classification Category for Infants of Adolescent and Non-Adolescent Mothers

Table 7: Means and (Standard Deviations) and Tests of Significance of 6 Self Report and Observation Measures (BDI, BSI, PSI, MSRI, CAPI, IBQ)

Table 8: Parameter Estimates for Logistic Regression Model 
Attachment Classifications Among 18-Month-Old Children of Adolescent Mothers

\section{Introduction}

Given the recent interest in examining the mother-child relationship among children of adolescent parents, it would seem logical to examine the affectional tie or bond between the two. This tie is often referred to as the attachment relationship between a mother and child. However, there have been relatively few studies that examine the nature of this relationship. This study attempts to examine the nature of the attachment relationship among children of adolescent mothers using a standard measure known as the Strange Situation procedure. This project will compare the attachment relationships of children of adolescent mothers with children of older, non-adolescent adult mothers.

\section{Adolescent Parenting}

Adolescent parenting is a topic that has received much press within the last few decades. It is thought that adolescent mothers may provide a poorer quality of parenting that may affect or determine the later attachment relationship as observed by the infants behavior in the Strange Situation (Lamb, Hopps, \& Elster, 1987). This link to attachment behavior will be discussed further, however, it is appropriate to first discuss the research pertaining to adolescent mothers.

There is considerable research that shows that the behavior of adolescent mothers is different than that of older mothers (Barratt \& Roach, 1995; Becker, 1987; Culp, Appelbaum, Osofsky, \& Levy, 1988; DeLissovoy, 1973; Elster, McAnarney, \& Lamb, 1983; Field, Widmayer, Stringer, \& Ignatoff, 1980; Garcia Coll, Hoffman, \& Oh, 1987; Garcia Coll, Vohr, Hoffman, \& Oh, 1986; Hubbs-Tait, Osofsky, Hann, \& Culp, 1994; 
Jones, Green, \& Krauss, 1980; Levine, Garcia Coll, \& Oh, 1985; McAnarney, Lawrence, \& Aten, 1979; Parks \& Arndt, 1990; Ragozin, Basham, Crnic, Greenberg, \& Robinson, 1982; Roosa, Fitzgerald, \& Carlson, 1982; Roosa \& Vaughan, 1984; Sandler, Vietze, \& O'Connor, 1981). In a variety of studies, with infants of varying ages, it has repeatedly been found that adolescent mothers vocalize less to their infants than non-adolescent mothers (Culp, et al., 1988; Garcia Coll, et al., 1987; Field, 1980; Jones, et al., 1980; Levine, et al., 1985; Roosa, et al., 1982; Sandler, et al., 1981). Adolescent mothers have also been described as engaging in fewer behaviors associated with parenting, such as touching or using a high pitched voice while speaking to the infant (McAnarney, et al., 1979). Most of these studies employed home based observations of maternal and infant behavior. These results have been found in samples of varying ethnic, racial, and socioeconomic groups.

Adolescent parents are more likely to behave in ways that are different from nonadolescent parents (Elster, et al., 1983; Lamb, et al., 1987). For instance, younger mothers are less sensitive to their infant's cues and exhibit less interactive sensitivity than older mothers (DeLissovoy, 1973; Ragozin, et al.,1982). They have also been found to exhibit less emotional and verbal responsivity than non-adolescent mothers (Barratt \& Roach, 1995; Garcia Coll, et al., 1986). Jones, Green, and Krauss (1980) reported that mothers aged seventeen to eighteen years old were less responsive to their infants than mothers aged twenty-one to twenty-three years of age.

As we will see later, all of the above factors as well as psychosocial indices may be important influences in later development. Specifically, Hurlbut, Culp, Jambunathan, and 
Butler (1997) assert that maternal self-esteem may be a good predictor of adolescent parenting.

Adolescent mothers may provide a less optimal environment for their children than do non-adolescent mothers (Garcia Coll, et al., 1987). Observation of the home environments of adolescent mothers revealed them to be less appropriate, in that adolescent mothers are providing less stimulation or less consistent learning environments for their infants (Garcia Coll, et al., 1986; Parks \& Arndt, 1990). Adolescent mothers smile less and show toys to their infants less often than non-adolescent mothers (Barratt \& Roach, 1995). Adolescent mothers interact more negatively with their infants (Culp, et al., 1988). They tend to be more restrictive, irritable, hostile, and punitive to their infants (DeLissovoy, 1973; Garcia Coll, et al., 1986). Teenage mothers who scored poorly on a parent-infant interaction scale were more likely to be communicatively demanding or protesting with their infants (Flanagan, Coppa, Riggs, \& Alario, 1994). Furthermore, adolescent mothers are more likely to choose physical modalities (poking and pinching) for interactions rather verbal modalities (Lawrence, McAnarney, Aten, Iker, Baldwin, \& Baldwin, 1981).

The differences in the environments provided and interactions given may be due to the fact that adolescent mothers tend to know less about child development (Roosa \& Vaughan, 1984) and have a poorer understanding of their infant's developmental abilities and needs (Parks \& Arndt, 1990). They tend to expect behaviors of walking, talking, or toileting several months early (DeLissovoy, 1973). Teenage mothers also tend to have a more negative attitude toward parenting (Roosa \& Vaughan, 1984). They also tend to 
rate their infant's behavior or temperament as being more difficult than do non-adolescent mothers (Field, 1980).

It is thought that infants of adolescent mothers fare less well than infants of older mothers. Adolescent parenthood has been correlated with maltreatment of their children (McCullough \& Scherman, 1998; Zuravin, 1988). For example, children of adolescent mothers are at increased risk for experiencing physical abuse (Miller, 1984). Also, Flanagan, Garcia Coll, Andreozzi, and Riggs (1995) examined the risk of adolescent mothers maltreating their children and found that living apart from related adults was a strong risk factor associated with maltreatment, as measured by a substantiated case by the state child protective agency.

There also has been research that links differences in maternal characteristics of self-esteem and depression among adolescent mothers to adverse child outcome (HubbsTait, et al., 1994). Furthermore, children of teenage mothers are thought to be at risk for cognitive impairments such as developmental delays or later academic failure (Baldwin \& Cain, 1980; Becker, 1987; Furstenburg, Brooks-Gunn, \& Morgan, 1987; Whitman, Borkowski, Schellenbach, \& Nath, 1987; Zuravin, 1988).

The above research suggests that adolescent parents may provide less optimal or less sensitive caregiving to their infants, which may in turn, have implications for later child outcome or parent-child relationships. Thus, it seems possible that adolescent parenting may lead to disturbances in the mother child attachment relationship. However, the literature is not conclusive, because as we will see, this is a topic that is relatively new in the literature and has not been fully explored. A more complete review will be 
explained later, but first it is important to discuss the nature of attachment and the theory surrounding it.

Attachment

It is thought that attachment theory originated with John Bowlby. Bowlby (1969) thought that all infants have an inborn need for social interaction and that this need usually becomes focused on a specific figure. He postulated that it may be of survival value for an infant to seek the protective closeness of certain adults and as a result, these infants should be equipped with specific behaviors to attain that closeness. For instance, we see examples of this, when we witness a baby cry or smile. Bowlby (1969) also suggested that adults are also equipped with caregiving behaviors intended to compliment the infant's behaviors. However, Bowlby was a psychoanalyst and thought that there may be more at work here. He argued that an infant and his caregiver share an affectional tie (Bowlby, 1969). Through this tie they seek to be close to this caregiver and also to maintain the contact with the caregiver, particularly when under stress. Over the course of the first year of life, the child exhibits behaviors that illustrate this desire to maintain closeness such as, turning toward the caregiver, crying, smiling, reaching, clinging, etc. Bowlby (1969) maintains that these are goal directed behaviors focused around a specific caregiver. Most often the caregiver we speak of is the child's mother, and this individual is most often the child's first attachment figure. Also, most of the empirical research done in attachment has focused on the relationship between a mother and her infant. According to Bowlby (1969), the infant's daily experiences with the caregiver contribute to an internal representation of the caregiver. This representation has been termed a "working model." 
Closeness to the attachment figure provides protection and a sense of security. Thus, the child's daily experiences have led him to construct a working model of his caregiver as one of trust and security. Bowlby (1969) also predicted consequences regarding a child's working model of a mother who is unavailable. However, Ainsworth and her colleagues were the first to test this theory empirically (Ainsworth \& Witting, 1969; Ainsworth, Blehar, Waters, \& Wall, 1978).

A major step in attachment measurement occurred when Mary Ainsworth (Ainsworth, et al., 1978) developed a standardized procedure for measuring the quality of attachment to the mother in infants 12 to 21 months old. This procedure is thought to reflect the infant's understanding and expectations of the mother's behavior or to reflect the "working model" that the child has created of his/her caregiver.

The Strange Situation is a laboratory procedure consisting of eight episodes in which the mother and child interact with each other and a stranger unknown to the infant, separate from each other, and then are reunited all in an environment that offers the child an opportunity for exploration. As the procedure progresses, each episode is considered to be more progressively stressful to the child. The strategy the child uses to cope with these stressors is indicative of the attachment relationship or working model he/she has constructed of his/her mother (Ainsworth, et al., 1978). Children are classified according to the pattern of behavior they exhibit throughout the Strange Situation but primarily for the behavior they show in the reunion episodes following the separations. The infant is assigned to a category according to the system defined by Ainsworth, et al. (1978). The first category is secure. Secure infants use their mother as a secure base from which to explore the environment. They derive comfort from their caregiver and this is illustrated 
by the child's attempts to be close to the caregiver (i.e., proximity-seeking and contactmaintaining behaviors) and also by the child's willingness to explore the environment. Secure infants are usually consoled by contact with the mother and easily move back to exploration, perhaps with brief checks on the mother.

The second category is insecure-avoidant. Avoidant infants show behaviors of avoiding interactions with or proximity to the mother. In fact, the infant may actively avoid the mother upon reunion, ignore social bids from mom, and/or avoid eye contact. The third category is insecure-resistant. Resistant infants may show a mixture of seeking contact while at the same time pushing away or refusing to be comforted by the mother. Their responses to the mothers return may seem ambivalent in quality. They may display anger towards their mother during reunions or refusal of her offering of toys or interaction. Resistant infants may show persistent pouting, whining, or tantruming behaviors.

Main and Solomon (1990) determined that some infants do not show a clear pattern of handling separations and then reunions. They do not seem to employ any of the behavioral strategies described above. Therefore, a final category was proposed which may occur in the presence of a secure or insecure attachment relationship. This category is called disorganized or disoriented. Disorganized infants show odd, disoriented, disorganized behavior or a combination of both avoidant and resistant behavior. Other behaviors that are indicative of disorganization are marked stilling or freezing in contact with the caregiver, anomalous postures, dazed avoidance, or demonstration of fear or apprehension of the caregiver. Main and Solomon (1990) state that these behaviors may 
reflect a child who is in conflict with or has feelings of fear or confusion regarding their caregiver.

The prevalence in the population for each of the Ainsworth categories seems to be relatively consistent. A meta-analysis of 39 studies indicated similar distributions of security $(65 \%)$, resistance (14\%), and avoidance (21\%) (Van Ijzendoorn \& Kroonenberg, 1988). Research also shows that the classifications tend to be relatively stable over time. Stability of these classifications in infants between 12 to 18 months of age has ranged from 53\% to $96 \%$ (Thompson, Lamb, \& Estes, 1982; Lamb, et al., 1985; Waters, 1978). In terms of long term stability, it has been reported that infant attachment classifications have predicted attachment classifications in six year old children (Main \& Cassidy, 1988).

The newer disorganized category has been found to be a relevant category in clinical samples such as maltreated infants or those with depressed mothers (Crittenden, 1985; Radke-Yarrow, Cummings, \& Kuczynski, 1985; Spieker \& Booth, 1988). The prevalence of disorganization in nonclinical samples however, appears to be between $10 \%$ to $15 \%$ (Cicchetti, 1987).

Maternal Predictors of Attachment

Most of the attachment research has focused on providing links from maternal behaviors to each of these attachment categories. Ainsworth, et al. (1978) assert that sensitivity to the infant's cues is a prerequisite for secure attachments. Mothers of infants with secure attachments have been described as sensitive to their child's cues, responding appropriately to these cues, and being available to their infants (Ainsworth, et al., 1978; Belsky, Rovine, \& Taylor, 1984; Egeland \& Farber, 1984; Grossmann, Grossmann, 
Spangler, Suess, \& Unzner, 1985). Mothers of avoidantly attached infants have been described as insensitive, rejecting, and unavailable to their infants, whereas mothers in resistant relationships are seen as lacking appropriateness and consistency in response to their infant's cues (Ainsworth, et al., 1978; Belsky, et al., 1984; Egeland \& Farber, 1984; Grossmann, et al., 1985). Thus, it does seem that these maternal behaviors do play an influential role in the quality of the attachment relationship (Ainsworth, 1984)

Further research has focused on providing links from maternal or environmental characteristics to the child's attachment classification. Stress in the family may be one contributor to insecure attachment classifications. Vaughn, Egeland, Sroufe, and Waters (1979) found that the change from secure to insecure from twelve to eighteen months was associated with increased stress. Tronick, Ricks, and Cohn (1982) found that mothers of secure group infants rated themselves significantly higher on self-esteem and competence. However, Seifer, Sameroff, Dickstein, Keitner, Miller, Rasmussen, and Hayden (1996) did not find an association between maternal characteristics or environment and attachment. Only a moderate correlation between major depression and attachment status was evident. Yet, the role of maternal psychopathology in attachment classification is somewhat contradictory.

A recent meta-analysis determined that parental mental illness was related to attachment classifications (Van IJzendoorn, Goldberg, Kroonenberg, \& Frenkel, 1992). However, most of the studies included did not use the Strange Situation procedure (Seifer, et al.,1996). Specifically, maternal depression has been found to be related to increased rates of insecure attachment on a preschool measure of attachment (Teti, Gelfand, Messinger, \& Isabella, 1995). It does seem reasonable that having the experience 
of a caregiver who has been unavailable due to depression may lead the child to expect that his mother cannot be relied upon thus, in turn affecting the attachment relationship (Seifer \& Schiller, 1995). However, Radke-Yarrow, Cummings, Kuczynski, and Chapman (1985) did not find any disproportionate differences in attachment among depressed mothers.

Child maltreatment has also been offered as a predictor of insecure attachment. Egeland and Sroufe (1981) state that when maternal caregiving is of an extremely poor quality there is an increase in insecure attachment. Specifically, there were more resistant types of insecure attachment in 12 month old infants among caregiving patterns of abuse and neglect. At 18 months, the avoidant type of insecurity was more common among the same caregiving patterns. Other studies have also found higher rates of insecurity among maltreated children (Crittenden, 1985; Schneider-Rosen, \& Cicchetti, 1984).

Infant Predictors of Attachment

Although most of the research on attachment concerns maternal predictors, there has been recent interest in examining characteristics of the infant that may affect attachment status. The relationship between attachment security and the child's temperament remains controversial. Essentially, the question is whether the behaviors and affect viewed in the Strange Situation can be attributed to intrinsic temperament of the child or the attachment relationship. Sroufe (1985) argues that temperament and attachment are essentially two different constructs. Yet, negative temperament has been shown to be correlated with increased crying and resistance in the Strange Situation (Vaughn, Lefever, Seifer, \& Barglow, 1989). Infant distress at 3 and 9 months of age was 
associated with insecurity at 12 months of age, although the authors also found that these observed differences may have been influenced by differences in maternal behavior (Belsky, et al., 1984). However, Vaughn, Stevenson-Hinde, Waters, Kotsaftis, Lefever, Shouldice, Trudel, and Belsky (1992) offer that most temperament rating scales include information about the child's behavior in the context of the parent-child interactions and it is logical that the parent-child relationship may influence the parent's ratings of the child's temperament. They further claim that it may be helpful to view temperament and attachment as falling on a continuum of assessment possibilities rather than as separate distinct entities (Stevenson-Hinde, 1988, as cited in Vaughn, et al., 1992).

Given that insecure attachment is more likely to occur when maternal behavior is of an inconsistent level (Ainsworth, et al., 1978) in addition to the other factors that may affect the attachment relationship, coupled with the research on adolescent mothers, one may suspect that there is a disproportionate amount of insecurity among infants of adolescent mothers.

Of the relatively few studies that have examined the attachment behavior of infants of adolescent mothers, only four utilized the Strange Situation as a measure of attachment quality. Lamb, et al. (1987) hypothesized that because of the assertion that avoidant attachments are related to intrusive maternal behavior (Ainsworth, et al., 1978) there would be a disproportionate amount of infants classified as insecure avoidant. The authors conducted the Strange Situation procedure when a sample of 40 infants were 14 months of age (Lamb, et al. 1987). They reported significantly more avoidantly attached infants in their sample of adolescent mothers as opposed to other samples of nonadolescent mothers, specifically the Ainsworth, et al. (1978) sample (Lamb, et al. 1987). 
Other studies have also reported lower rates of security among infants of adolescent mothers. Frodi and colleagues investigated two indices of socio-emotional development (attachment and mastery motivation) in infants of adolescent mothers as compared to infants of adult mothers (Frodi, Grolnick, Bridges, \& Berko, 1990). Here, the authors found that among the total sample of 63 infants, the distribution of secure attachment was slightly lower in the group of infants of adolescent mothers. Later Chisquare analysis determined this difference non-significant.

Another study, conducted by Broussard (1995), utilized a modified version of the Strange Situation, using only one separation and reunion. This study classified infants into one of four classifications; secure, avoidant, resistant, and disorganized. In her sample of 38 infants of adolescent mothers, a lower proportion of secure attachment was found. When compared to another sample that also included disorganization as a category, comparisons of secure vs. insecure were statistically different. Although, it is unclear whether this second sample utilized the same modified version of the Strange Situation. Broussard (1995) further tries to examine differences in attachment according to race. Fewer black infants were classified as secure than were white infants (Broussard, 1995). Ward and Carlson (1995), in their study of adolescent mothers from environments characterized by poverty and stress, did not find higher proportions of insecurity among their 15-month-old infants.

Given the paucity of research on attachment among infants of adolescent mothers, the rational for conducting this study was to supplement an existing weak literature base. A question that flows naturally from this is, is there a difference in the presence of insecurity among children of adolescent mothers in comparison to children of non- 
adolescent mothers. If differences in attachment classification are determined, can they be explained by maternal characteristics? The major prediction of this study was that there would be a significantly higher proportion of insecurity among 18-month-old infants of adolescent mothers. Also, there would be a higher proportion of disorganization among the infants of adolescent mothers. The secondary predictions for this project were that differences in maternal characteristics, maternal perception of infant behavior, and environment for the infants of adolescent mothers would explain differences in attachment security. Specifically, there would be higher levels of depression, stress, psychological distress, child abuse potential, and higher ratings of difficult infant behaviors, as well as lower self-esteem among the adolescent mothers which in turn would increase the probability of insecurely attached 18-month-old infants. 


\section{Method}

\section{Participants}

The participants in this study were 140 mothers and their 18-month-old infants.

All subjects were initially recruited to be part of a prospective study aimed at examining the effects of maternal lifestyles during pregnancy on a variety of infant outcomes. The larger maternal lifestyles study (MLS) is a multi-site, longitudinal study that began recruiting mothers and their infants in 1991. This study is funded by the National Institute of Child Health and Development (NICHD), National Institute on Drug Abuse (NIDA), Association for Children, Youth and Families (ACYF), and Council on Substance Abuse Treatment (CSAT). The mother infant dyads were seen at regular scheduled intervals (1, $4,8,10,12,18,24,30,36$, and 48 months) either in the laboratory or in the infant's home. All infants were seen within a two week window on either side of the scheduled interval. A variety of data concerning infant outcome and possible family or maternal predictors or confounding variables were collected at each of the visits either by evaluation, observation, or self report. One of the specific aims of MLS is to determine what effect illicit substance abuse during pregnancy may have upon infant outcome. Maternal substance abuse was determined both by self report and drug testing of the infant's first stool or meconium. If positive identification was made then the infant was recruited for the follow up phase of the study and efforts were made to obtain an infant for the control group. Infants in the control group were not exposed to cocaine and / or opiates during pregnancy as confirmed by meconium testing and were also matched for sex, gestational age, and birth weight. 
Exclusionary criteria for MLS included presence of a chromosomal abnormality, multiple births, and mothers less than eighteen years of age. Since adolescence was an exclusionary criterion, all mothers in the MLS study are over the age of eighteen. The mean age of the mothers at recruitment is approximately 26 years of age. An ancillary project to study this excluded cohort of adolescent mothers with the same protocol as MLS was approved by all the principal investigators in the MLS study and thus, these mother infant dyads were recruited at the same time as the larger MLS sample. The ancillary was only conducted at the Providence, Rhode Island site. This group of adolescent mothers does not contain any abuse of cocaine and / or opiates as obtained by maternal report and meconium testing.

For inclusion into the current study, participants had to attend the eighteen month visit, had to have been living with their biological mother since birth, and also had to have their biological mother as their primary caregiver.

The sample of 140 mothers comprised the subjects in two groups. The first group consisted of 60 eighteen-month-old infants born to adolescent mothers in Providence, Rhode Island. This group is approximately $60 \%$ of the total sample in the adolescent ancillary study to the larger maternal lifestyles project. The second group consisted of 80 eighteen-month-old infants and their mothers born in Providence, Rhode Island. This group was taken from the controls in MLS since the adolescent sample does not contain exposure to cocaine and / or opiates. This comprises approximately $80 \%$ of the control group of the MLS Providence site. Both groups of infants were born roughly at the same time. Both groups of infants and mothers were recruited at the time of the infant's birth and agreed to participate in follow up visits. The procedures for the follow up visits were 
the same for all subjects. Since the primary hypothesis of the study concerns the infant's attachment classifications to his biological mother, it is important to note that some of the subjects are not included in the present analyses. Eight subjects were not included from the adolescent group because some did not complete a strange situation paradigm or technical problems were experienced during videotaping (6), or the mother was not present for the assessment and another caregiver was used (1), or the assessment was deemed uncodeable due to the examiner or mother wishing to discontinue the procedure

(1). A final subject was dropped from the adolescent sample because the mother was not the primary caregiver. The remaining 51 subjects comprised the adolescent sample. For the older mother sample, four subjects were dropped from the analyses. In one of these, the mother was not the primary caregiver. The remaining three procedures were either not completed or not videotaped. Therefore the total number of subjects in the nonadolescent sample was seventy-six.

\section{Procedure}

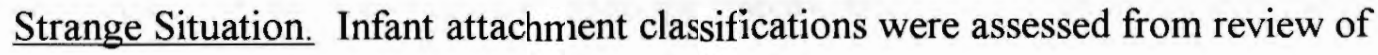
videotaped sessions of Ainsworth's Strange Situation procedure (Ainsworth, et al., 1978). The Strange Situation is a laboratory procedure consisting of eight episodes in which the mother and child interact with each other and a stranger unknown to the infant, separate from each other and then are reunited all in an environment that offers the child an opportunity for exploration (Table 1). 
Table 1

Strange Situation Procedure

Episode 1 - Mother and baby - 20 seconds

Episode 2 - $\quad$ Mother and baby -3 minutes

Episode 3 - $\quad$ Stranger enters and sits - $1 \mathrm{~min}$

Stranger talks to Mother - $1 \mathrm{~min}$

Stranger plays with baby - $1 \mathrm{~min}$

Episode 4 - $\quad$ Mother leaves the room, Stranger remains - 3 min

First Separation

Episode 5 - $\quad$ Mother returns, Stranger leaves the room - $3 \mathrm{~min}$

First Reunion

Episode 6 - Mother leaves the baby alone - $3 \mathrm{~min}$

Second Separation

Episode 7 - $\quad$ Stranger returns $-3 \mathrm{~min}$

Episode 8 - $\quad$ Mother returns, Stranger leaves $-3 \mathrm{~min}$

Second Reunion

Scoring depends on review of each episode but primarily the two reunion episodes (Ainsworth, et al., 1978). Each child is rated for specific behaviors at each reunion (see Appendix A). These consist of Proximity-Seeking, Contact-Maintaining, Avoidant, and Resistant behaviors. These behaviors are rated on a 7-point Likert-type scale in which a higher score reflects more of the behavior. Proximity-seeking behavior can be described as attempts to be close to the caregiver. Presumably the separation has caused some distress in the infant which would lead him to approach the mother upon her return. Contact-maintenance refers to the child trying to maintain contact with the caregiver. For example, the child may cling to the mother or resist being put down when held. Avoidant behavior reflects attempts from the infant to move away from or ignore the caregiver. The 
avoidant behaviors can range from a brief look away from the mother to a full snub of the mother's return regardless of the mother's bids for contact or interaction, if any. Resistant behavior is evidenced in the infants desire for contact but also in the resistance of comforting, and the inability to be soothed. Resistant behaviors can range from crying after having been comforted by the caregiver to a full blown tantrum. From this information, specifically the scores on the above four behaviors, the dyad is then categorized into one of three general categories (Table 2). The first category is secure or commonly referred to as type B. Secure (B) infants derive comfort from their caregiver and this is illustrated by the child's attempts to be close to the caregiver (i.e. proximity seeking and contact maintaining behaviors) and also by the child's willingness to explore the environment. The second category is insecure-avoidant or commonly referred to as type A. Avoidant infants tend to show very little proximity seeking behaviors and may actively avoid the mother upon reunion. The third category is insecure-resistant or C. Resistant infants may show a mixture of seeking contact while at the same time pushing it away or refusing to be comforted by the mother.

Table 2

Attachment classifications
A - Avoidant
B - Secure
C - Resistant

Separation Episodes Child shows little Episodes 4 and 6 distress.

May or not be distressed. Makes efforts to search for mother.

Reunion Episodes Episodes 5 and 8
Child snubs or avoids mother.
Child comforted by mothers return and makes efforts to contact and/or greet her.
Child shows much distress

Child may refuse to be comforted and seeks and rejects contact. 
A final category is also determined and may occur in the presence of security or insecurity. This category is disorganization (D) and is also rated on a 7 point Likert type scale (Main and Solomon, 1990). A higher score reflects more D behavior or a clear theme or pattern of disorganization. Disorganized infants show odd, disoriented, disorganized behavior or a combination of both avoidant and resistant behavior. For example, infants may approach the stranger at the moment of reunion after showing much distress or infants may show apprehension of the mother by backing away from her at reunions. Infants are assigned a level of $\mathrm{D}(1-7)$ based upon their behaviors and then are classified as disorganized or not disorganized.

The A,B,C classifications have been reliably identified in 39 studies in eight countries and prevalence rates have been reported earlier (Van Ijzendoorn \& Kroonenberg, 1988). Stability of these classifications in infants between 12 to 18 months of age has ranged from $53 \%$ to $96 \%$ (Thompson, Lamb, \& Estes, 1982; Lamb, et al., 1985; Waters, 1978). In terms of long term stability, it has been reported that infant attachment classifications have predicted attachment classifications in six-year-old children (Main \& Cassidy, 1988). The predictive validity of the strange situation had shown that insecurity predicts behavior problems later on (Erickson, Sroufe, \& Egeland, 1985; Turner, 1991)

Maternal Characteristics. Since maternal characteristics have been shown to be related to patterns of caregiving and later attachment (Ainsworth, et al., 1978), several measures were also assessed in both samples (Table 3). These measures were gathered by the larger MLS study by examiners trained to administer each, if appropriate. All 
adolescent data was scored by this examiner. Copies of the instruments used in the current study from the larger MLS study are included in Appendixes B-H. Use of the MLS forms requires permission granted by the National Institute of Health $(\mathrm{NIH})$.

First, the Home Observation for Measurement of the Environment (HOME) (Caldwell \& Bradley, 1984) was used (see Appendix B). This instrument is useful for measuring the social-emotional support available within the infant's home (Caldwell \& Bradley, 1984). The 45 scale items are scored on the basis of observations of the home and on interviews with the mother. This tool was administered at the 10 -month visit by an examiner working on the larger maternal lifestyles project. The items are then subdivided into dimensions including Responsivity of Parent, Acceptance of Child Behavior, Organization of Environment, Appropriate Play Materials Provided by Parent, Variety of Daily Stimulation, and Total Quality of Home Environment. Only the total score was used in this study. This tool has been found to be both reliable and valid (Caldwell \& Bradley, 1984). Internal consistency for the Total score ranges from .44 to .89 . Temporal stability of the HOME ranges from .3 to .7 for time periods ranging from six months to two years. Validity has been established by obtaining correlations with performance on cognitive measures and behavioral records (i.e., Bayley Scales of Infant Development). These correlations range from .3 to .7 , depending upon the age at which the relationship was examined. The correlations tended to become stronger up to age three.

Parenting stress was measured using the Parenting Stress Inventory (PSI) (Abidin, 1983). The 36 item short form was used and was collected at the four-month scheduled visit. It was administered by interview to the mother by an examiner working on the larger maternal lifestyles study (see Appendix C). The PSI measures stress arising from 
parenting. The mother rates each item on a five point likert scale ranging from strongly agree to strongly disagree. The PSI yields three subscales and a summary index of total stress. Only this summary index was used in this study. Higher scores reflect greater stress. The norms for the PSI reveal the mean to be 71.

Next, a measure of child abuse potential was assessed. The Child Abuse Potential Inventory (CAPI) (Milner, 1980) is a 77 item self-report scale that examines maternal psychological difficulties such as distress, rigidity, and unhappiness and also interactional problems experienced by the mother such as problems with self, family, or others. This instrument was obtained at the 8 month scheduled visit (see Appendix D). Scores are generated for each of the factors and a total score. Once again only the total score was used in this study. Psychometric properties such as reliability and validity have been established (Milner, 1980). Internal consistency for the CAPI ranges from .92 to .98 and temporal stability from .91 to .75 for time periods of one day and three months respectively. Construct validity has been established by obtaining correlations with measures of parental stress and also the family environment. These correlations are from .62 and 41 , respectively. Also, Mee (1983, as cited in Milner, 1980) examined the relationship between the CAPI and attachment using the Interview Schedule for Social Interaction. Mothers who had high adequacy for attachment had lower scores on the CAPI.

Maternal depression was assessed using the Beck Depression Inventory (BDI) (Beck, Ward, Mendelson, Mock, \& Erbaugh, 1961) which was collected at the 4 month visit. The BDI is a 21 item self report scale written at a fifth grade reading level, that indicates the respondent's level of depression (see Appendix E). Scale item responses 
range from zero to three and items are summed to obtain an overall score. A higher score reflects a higher level of depression. The BDI has well established psychometric properties. It possesses good internal consistency, stability, and reliability. Split-half reliabilities range from .78 to .93 . Test-retest reliabilities have been reported from .48 with undergraduate populations after a time period of three months. The validity of the scale has been demonstrated with a number of other depression measures (Beck, Steer, \& Garbin, 1988).

Maternal psychological distress was determined by the Brief Symptom Inventory (BSI) (Derogatis, 1993). It is a 53 item questionnaire that is the short form of the Revised 90 item Symptom Checklist (SCL-90-R). The BSI was administered by interview to the mother at the four month visit by an examiner working on the larger MLS project (see Appendix F). The BSI yields 9 primary symptom dimensions as well as a global severity index. Higher scores reflect more reported symptoms. Only the global score was used in this study.

Maternal self-esteem was assessed via the Maternal Self-Report Inventory (MSRI) (Shea \& Tronick, 1988) which was collected at the 10 month visit (see Appendix G). The MSRI is a 26 item scale that yields a total score which reflects the mothers self-esteem. A higher score indicates increased self-esteem. It has been shown that maternal self-esteem influences the quality of a mother's behavior with her infant (Shea \& Tronick, 1988). Test-retest, concurrent, and constructive validity for the MSRI have been established (Shea \& Tronick, 1988). Concurrent validity was determined by correlations between another self report inventory and clinical ratings of maternal self-esteem. Correlations were .74 and .35 respectively. Construct validity was obtained by correlations between 
the MSRI and other independent measures such as family support (.69), maternal perception of the infant (.36), and maternal infant interaction (.33). Reliability was obtained by a four week test-retest reliability coefficient of .85 .

Infant Characteristics. Information on the infant's temperament and behavior was also obtained to help explain any differences that may have been found. There is some controversy as to whether infant characteristics are significant predictors of attachment security. To address this, the Infant Behavior Questionnaire (IBQ) (Rothbart, 1981) was used. The IBQ is a 90 item questionnaire administered to the mother at the four month visit to measure her perceptions of the infant's temperament and behavior in common everyday situations (see Appendix H). This measure yields six summary scales: Activity Level, Smiling and Laughter, Distress to Approach Sudden or Novel Stimuli, Distress to Limitations, Soothability, and Duration of Orienting. These summary scores have coefficient alpha values ranging from .72 to .85 . Stability correlations range from .43 to .80 for time periods of 9 months to 12 months (Rothbart, 1981). 
Table 3

\section{Measures}

Procedure

$\begin{array}{ll}\text { Visit } & \begin{array}{l}\text { Domain } \\ \text { Attachment }\end{array}\end{array}$

Strange Situation

18 month

\section{PARENT REPORT}

Beck Depression Inventory

4 month Depression

Brief Symptom Inventory

4 month Psychological Distress

Parenting Stress Inventory

4 month Parenting Stress

Child Abuse Potential Inventory

8 month Child Abuse Potential

Maternal Self-Report Inventory

10 month Self Esteem

Infant Behavior Questionnaire

4 month

Maternal Perception of Infant
Temperament

\section{OBSERVATION}

Home Observation for Measurement

10 month Social, Emotional, and

of the Environment

Cognitive Support in the Home

Demographics. Demographics of the participants obtained throughout the larger study were also collected to describe the samples further. These include such variables as maternal education, socioeconomic status, race, parity, number of prenatal care visits, birthweight, gestational age, gender, apgar scores at one and five minutes after birth, and extent of alcohol, marijuana, and cigarette use of the mother during pregnancy.

Socioeconomic status was determined by a method of combining such factors as education, income, occupation, and other contributors to the household. It is similar to the Hollingshead Four Factor Index of Social Position (Hollingshead, 1975), although it is 
measured on a continuous rather than a categorical scale. Twenty-nine through thirty-nine constitutes middle class, less than twenty-nine constitutes lower socioeconomic levels, and greater than thirty-nine constitutes higher socioeconomic levels.

Data Reduction. Strange Situation procedures of the adolescent group were coded by this examiner trained to classify infants according to Ainsworth's classification procedure for A, B, and C (Ainsworth, et al., 1978) and Main and Solomon's procedure for Disorganization (Main \& Solomon, 1990). Training on the scoring system occurred over approximately a time period of two years by a trained examiner, Ron Seifer, Ph.D.

Reliability of the adolescent sample was evaluated on approximately $20 \%$ of the sample by an independent coder also trained at the time of this examiner (S.B.). Interrater reliability of $94 \%$ was determined by using the percent agreement criterion for the $20 \%$ recoded for reliability. The Strange Situation procedures of the non adolescent sample were coded by either this examiner or the above mentioned coder.

Given the nature of the adolescent sample, it would have been hard for this examiner to remain blind to group assignment. Essentially, adolescents may look younger than their non-adolescent counterparts thus making it difficult for any coder to remain blind to group status. To help address this fact and strengthen this study, a group of mothers from the larger MLS study who were between the ages of eighteen and twenty at the time of recruitment were identified (11). The Strange Situation procedures of this group of younger non-adolescent mothers were included with those of the adolescent sample. Thus, these procedures were rescored to help address the issue of blindness to group assignment. The recoded classifications for these subjects revealed the same original classifications. 
Occasionally, it was difficult to determine a definitive attachment classification.

When these situations arose, the procedures were conferenced among trained examiners. In the current sample three procedures were conferenced and agreement was obtained.

Given the prevalence data of the specific secure and insecure attachment patterns (Van Ijzendoorn \& Kroonenberg, 1988) and the sample size in this study, all the insecure groups (both $\mathrm{A}$ and $\mathrm{C}$ ) were combined. Thus the rating for each infant will be classified as secure or insecure. Since the D classification can occur with or without the presence of security, Disorganization will also be categorized into two groups, presence of D or not. A power analysis was conducted to determine if a significant difference in the proportion of security/insecurity could be detected between these two groups. With the current sample size, the power analysis yielded a value of .87. According to Cohen (1988), this is enough power to conduct the study at hand. Since we know that the prevalence of security in normal populations tends to be approximately $65 \%$ (Van IJzendoorn \& Kroonenberg, 1988), and thus if the rate of security in the non-adolescent population is 25 points higher than the rate in the adolescent sample, then there is an $87 \%$ chance that the effect in this study will be 15 points or more to be significant. This means that the rate of security in the adolescent sample must be $40 \%$ (which computes to 21 subjects) in order to be significant. The power value indicates that there is an $87 \%$ chance that this difference will occur (Cohen, 1988). 


\section{Results}

\section{Analysis of Demographics}

To determine if there were differences between the two groups, a number of maternal and infant characteristics were examined. The demographics for the samples were compared using the $X^{2}$ statistic to describe the distributional differences for data that were categorical and with t-tests to compare mean values when data were continuous.

Maternal characteristics. The demographics for the two samples are presented in Table 4. As expected, there was a significant difference between the two groups of mothers on most of the maternal demographic characteristics.

Mothers in the non-adolescent sample were more likely to have more than one living child (parity) $(M=2.2)$ than the mothers in the adolescent sample $(M=1.1), t(87)=$ $-6.8, \mathrm{p}<.05$

A continuous measure of socioeconomic status or index of social position was computed for each participant. This value was derived from a variety of factors such as occupation, contribution to household income, education, etc. A higher score reflects higher socioeconomic status. Mothers in the older sample were more likely to have a higher socioeconomic status $(M=35.3)$ than the younger mothers $(M=25.5), \underline{t}(115)=$ $-5.3, p<.01$. The majority of the mothers in the adolescent sample had an index of social position which reflected the subjects were primarily in the lower and middle to lower socioeconomic groups. The majority of the subjects in the non-adolescent sample fell in the middle to upper middle class range.

Similarly, level of education as measured by number of years completed in school was significantly lower in the adolescent group. The older mothers had completed more 
years of school $(M=12.7)$ than the mothers in the adolescent sample $(M=9.2), \underline{t}(109)=$ $-10.3, \mathrm{p}<.01$

Marital status also differed between the two groups with a higher proportion of the non-adolescent mothers being married $\left(X^{2}=40.41, \mathrm{p}<.05\right)$. The distributions of race also differed between the two groups with a higher proportion of Hispanic women in the adolescent group and a higher percentage of Black women in the non-adolescent group $\left(X^{2}=16.7, \underline{p}<.01\right)$.

Dichotomous measures of alcohol, marijuana, and cigarette use were determined for each of the subjects. History was determined by yes or no for use during pregnancy. This information was collected at the initial recruitment interview in the hospital during the immediate post-partum period. The proportions of use differed between the two groups for each of the substances of alcohol and marijuana. A higher proportion of nonadolescent mothers reported having used alcohol during their pregnancy $\left(X^{2}=37.0, \mathrm{p}<\right.$ .01). A higher proportion of adolescent mothers reported having used marijuana during their pregnancy $\left(X^{2}=20.7, \underline{p}<.01\right)$. There was no difference between the two groups with respect to self-reported nicotine use during pregnancy. 
Table 4

Means and Standard Deviations or Frequencies and Tests of Significance for Maternal Demographic Characteristics of Sample by Maternal Age Group

$$
\underline{\text { Adolescent }} \quad \underline{\text { Non-Adolescent }} \quad \mathrm{t} / X^{2}
$$

Mother Characteristics

\begin{tabular}{|c|c|c|c|c|c|}
\hline \multicolumn{3}{|c|}{ Maternal Age } & $16.1(.9)$ & $28.6(5.7)$ & $-12.7^{*}$ \\
\hline \multicolumn{3}{|c|}{ Education (grade level) } & $9.2(1.2)$ & $12.7(2.8)$ & $-10.3^{*}$ \\
\hline \multicolumn{3}{|c|}{ Prenatal Care (\# visits) } & $14.1(6.5)$ & $12.7(4.8)$ & NS \\
\hline \multicolumn{3}{|c|}{ Parity } & $1.1(.3)$ & $2.2(1.4)$ & $-6.8^{*}$ \\
\hline \multicolumn{3}{|c|}{ Socioeconomic Status } & $25.5(7.3)$ & $35.3(12.8)$ & $-5.3 *$ \\
\hline \multirow{2}{*}{\multicolumn{3}{|c|}{$\begin{array}{l}\text { Marital Status } N \text { Married } \\
\qquad N \text { Not Married }\end{array}$}} & 1 & 40 & $40.41 *$ \\
\hline & & & 49 & 35 & \\
\hline \multirow{4}{*}{ Race } & White & & 12 & 16 & $16.7^{*}$ \\
\hline & Black & & 15 & 44 & \\
\hline & Hispanic & & 23 & 12 & \\
\hline & Other & & 0 & 3 & \\
\hline \multirow{2}{*}{\multicolumn{2}{|c|}{$\begin{array}{l}\text { Alcohol Use } \\
\text { during pregnancy }\end{array}$}} & Yes & 4 & 47 & $37.0^{*}$ \\
\hline & & No & 47 & 29 & \\
\hline \multirow{2}{*}{\multicolumn{2}{|c|}{$\begin{array}{l}\text { Marijuana Use } \\
\text { during pregnancy }\end{array}$}} & Yes & 16 & 2 & $20.7^{*}$ \\
\hline & & No & 35 & 74 & \\
\hline \multirow{2}{*}{\multicolumn{2}{|c|}{$\begin{array}{l}\text { Nicotine Use } \\
\text { during pregnancy }\end{array}$}} & Yes & 10 & 17 & NS \\
\hline & & No & 41 & 59 & \\
\hline
\end{tabular}

Infant characteristics. The demographics for the two samples are presented in

Table 5. There were no significant differences between the two groups on number of prenatal care visits, infant gender, birthweight, gestational age, and apgar scores at one and five minutes after birth. The percentages of males and females in the adolescent 
sample were $47 \%$ and $53 \%$, respectively, and the percentages of males and females in the non-adolescent sample were $53 \%$ and $47 \%$, respectively.

Although there were no differences in the mean birthweights of the infants in either group, it is important to describe the two samples further. The percentage of infants with birthweights less than 2500 grams was 13.7 in the adolescent sample and 25.3 in the nonadolescent sample. Similarly, the percentages for the amount of infants with gestational ages less than 37 weeks was 13.6 and 25.3 respectively. The percentage of infants with birthweights less than 2500 grams was converted into a dichotomous variable to determine if the proportion of infants with birthweights less than 2500 grams differed between the two groups. There was no significant difference between the two on this variable $\left(X^{2}=\right.$ $2.5, \underline{p}>.05$ ). Similarly, the percentages for the amount of infants with gestational ages less than 37 weeks was also converted into a dichotomous variable. Once again there was no significant difference between the two samples on the proportion of infants with gestational ages less than 37 weeks $\left(X^{2}=2.3, \underline{p}>.05\right)$.

Table 5

Means and Standard Deviations or Frequencies and Tests of Significance for Infant Demographic Characteristics of Sample by Maternal Age Group

Infant Characteristics

Gender $\mathrm{F}$

$\mathrm{M}$

Birthweight (grams)

Gestational Age (weeks)

Apgar 1 minute

5 minutes

$* \mathrm{p}<.05$
27

24

$3063.8(550.7)$

$38.5(2.9)$

$7.5(1.7)$

$8.6(1.1)$
35

40

$3005.4(803.5) \quad$ NS

$37.7(2.9)$

NS

$7.5(1.4)$

$8.6(.9)$

NS 


\section{Analysis of Attachment Classification}

It was predicted that there would be significantly more insecure infants among 18month-old infants of adolescent mothers. A power analysis was conducted to determine if a significant difference in the proportion of security/insecurity could be detected between these two groups. With the current sample size, the power analysis yielded a value of 87 .

First, it is important to describe the two samples in terms of their attachment classifications. Table 6 shows the distributions of the different attachment categories for each group. In the adolescent sample, approximately $66.7 \%$ of the infants were classified as secure (B), 17.7\% were classified as insecure-avoidant (A), and $7.8 \%$ were classified as insecure-resistant (C). In the non-adolescent sample, approximately $61.8 \%$ of the infants were classified as secure (B), 11.8\% were classified as insecure-avoidant (A), and 11.8\% were classified as insecure-resistant ( C). Due to the nature of the sample size, the two insecure categories of $\mathrm{A}$ and $\mathrm{C}$ were combined to create one insecure category; therefore, infants were categorized as either secure or insecure.

Occasionally, infants were unable to be classified into one of the three groups or exhibited behaviors that indicated the infants had a mixed strategy of both resistance and avoidance. One infant in the adolescent sample and six infants in the non-adolescent sample were unable to be classified. Three and five infants showed a mixed strategy of $\mathrm{A} / \mathrm{C}$ in the adolescent and non-adolescent samples respectively. 
Table 6

Number and (Percent) of Each Attachment Classification Category for Infants of Adolescent and Non-Adolescent Mothers

$\begin{array}{lcc} & \frac{\text { Adolescent }}{\mathrm{N}=51} & \frac{\text { Non-Adolescent }}{\mathrm{N}=76} \\ \mathrm{~A}-\text { Avoidant } & 9(17.7) & 9(11.8) \\ \mathrm{B}-\text { Secure } & 34(66.7) & 47(61.8) \\ \mathrm{C}-\text { Resistant } & 4(7.8) & 9(11.8) \\ \mathrm{U}-\text { Unclassifiable } & 1(1.96) & 6(7.9) \\ \text { A/C - Mixed Strategy } & 3(5.9) & 5(6.6) \\ \text { D - Disorganized } & 5(9.8) & 15(19.7)\end{array}$

At the same time, infants were rated as being disorganized (D) or not. Among the infants in the adolescent sample, $10 \%$ were classified as D and $19.7 \%$ of the infants in the non-adolescent sample were rated as disorganized.

To determine presence of security and insecurity categorically, infants classified as insecure via $\mathrm{A}, \mathrm{C}$, or $\mathrm{A} / \mathrm{C}$ classifications were all categorized as insecure and were compared to those infants classified as secure via B classifications. Since data were categorical (secure vs. insecure and adolescent, non-adolescent), a Two-Way Chi-Square analysis was utilized to determine the difference in the proportion of insecurity between the two groups $\left(X^{2}=.003, \mathrm{p}>.05\right)$. Another Chi-Square analysis was employed to determine the difference in the proportion of disorganization between the two groups $\left(X^{2}\right.$ $=.99, \mathrm{p}>.05)$. Neither of these Chi-squares was significant, indicating that there was no difference in the proportion of insecurity nor disorganization among the two groups. 
Since there was enough power in the study to determine differences if there were in fact any, one can assume that the lack of differences was not due to a Type II error.

\section{Analysis of Self Report and Observation Measures}

Additional analyses were conducted on variables that may predict attachment classification. These factors have been shown to be related to attachment security and insecurity. A series of analyses of group means in the form of t-tests were conducted for the BDI, PSI, BSI, HOME, MSRI, CAPI, and IBQ. Table 7 shows the means and standard deviations for each of the maternal self report measures and the home observation by group. The two groups did not differ in amount of maternal depression as measured by the BDI, $\underline{t}(100)=1.92, \underline{p}>.05$. On the MSRI, the mothers in the adolescent group reported significantly less self-esteem as a mother $(M=96.5)$ as opposed to the mothers in the non-adolescent group $(M=104.2), \underline{t}(100)=-4.3, \underline{p}<.01$. On the BSI, the two groups did not differ on the amount of symptoms reported as measured by the global severity index, $\underline{\mathrm{t}}(110)=1.95, \mathrm{p}>.05$. On the PSI, the mothers in the adolescent sample reported more stress arising from parenting $(M=80.0)$ as compared to the mothers in the non-adolescent sample $(M=65.43), \underline{t}(110)=5.21, \underline{p}<.05$. On the CAPI, the mothers in the adolescent group reported significantly more child abuse potential $(M=160.6)$ as opposed to the mothers in the non-adolescent group who had less child abuse potential (M $=103.14), \underline{t}(89)=2.8, \underline{p}<.01$. On the IBQ, the mothers in the two groups did not differ on any of the dimensions except for Activity Level. The adolescent mothers rated their infants as being significantly more active $(M=3.28)$ than infants of mothers in the nonadolescent group $(\mathrm{M}=2.95), \underline{\mathrm{t}}(108)=2.9, \underline{\mathrm{p}}<.01$. 
On the observational measure of the HOME, adolescent mothers provided a home

environment of poorer quality $(M=30.63)$ than mothers in the non-adolescent group ( $M$

$=35.56), \underline{\mathrm{t}}(107)=-4.2, \underline{\mathrm{p}}<.01$.

Table 7

Means and (Standard Deviations) and Tests of Significance of 6 Self Report and Observation Measures (BDI, BSI, PSI, MSRI, CAPI, IBQ)

$\underline{\text { Adolescent }} \quad \underline{\text { Non-Adolescent }} \quad t$

Beck Depression Inventory

Brief Symptom Inventory

Parenting Stress Inventory

Maternal Self Report

Inventory

Child Abuse Potential

Inventory

Infant Behavior

Questionnaire

Activity Level

Smiling and Laughter

Distress to Sudden Stimuli

Distress to Limitations

Soothability

Duration of Orienting

HOME

${ }^{*} \mathrm{p}<.01$
$10.27(9.3)$

$.71(.61)$

$80.00(13.68)$

$96.50(6.4)$

$160.55(87.6)$

$103.14(96.5)$

$2.8 *$

NS

NS

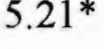

$104.16(11.8) \quad-4.3^{*}$
$3.28(.6)$

$3.45(.7)$

$2.21(.6)$

$2.42(.5)$

$3.28(.7)$

$2.85(.5)$

$30.63(5.5)$
$2.95(.6)$

$3.48(.7)$

$2.07(.6)$

$2.50(.5)$

$3.12(.7)$

$2.73(.6)$

$35.56(6.4)$ 


\section{Additional Analyses}

A logistic regression was performed to determine what effect maternal age as measured by the two sample groups and the other related maternal characteristics which proved significant, may have on determining the probability of insecure attachment. A logistic regression is used when the dependent variable is measured on a nominal scale and is dichotomous and there are two or more explanatory variables. The model gives the probability that the outcome occurs as an exponential function of the independent variables. Here, the purpose was to determine if the probability of an infant having an insecure attachment to his mother could be explained by such factors as maternal age, selfesteem as a mother, child abuse potential, quality of the home environment, and maternal perceptions of infant temperament and behavior. Only those measures that differed significantly between the two groups were used in the logistic regression (Table 8). The logistic regression did not significantly explain attachment security by any of the above factors. $\left(X^{2}=5.6, \underline{p}>.05\right)$.

Table 8

Parameter Estimates for Logistic Regression Model

Adolescent/Non-adolescent

Parenting Stress

Self Esteem

Child Abuse Potential

HOME

Maternal Perception of Infant

Temperament (Activity Level)

Race

Socioeconomic Status $\underline{\beta}$

\section{$\underline{\mathrm{SE}}$}

.637

.022

.011

.001

$-.071$

.159

.058
.681

.024

.031

.003

.051

.507

.378

.032
Odds Ratio Confidence Interval 95\%

$.139 \quad 2.01$

$.935 \quad 1.03$

$.932 \quad 1.05$

$.992 \quad 1.01$

$\begin{array}{ll}.972 & 1.19\end{array}$

$.316 \quad 2.30$

1.17

1.15

$\begin{array}{ll}.428 & 1.88\end{array}$

$\begin{array}{ll}.886 & 1.00\end{array}$ 


\section{Discussion}

The purpose of this study was to examine the attachment relationship of 18month-old infants of adolescent mothers as compared to non-adolescent mothers. The study further attempted to examine this relationship in the context of maternal characteristics such as depression, self-esteem, parenting stress, child abuse potential, psychological distress, perception of infant behavior, as well as the caregiving environment.

It was suspected that infants of adolescent mothers would have greater incidences of insecure attachment and disorganization as compared to infants of non-adolescent mothers. It was also suspected that these differences could be explained by such factors as depression, self-esteem, parenting attitudes, as well as the caregiving environment. These hypotheses were not confirmed in the present study.

Given the nature of the two samples, it is reasonable to expect that these two groups would differ demographically. Understandably, the adolescent mothers also differed on other demographic variables that defined the nature of this group. Education levels of the adolescent mothers were significantly lower than that of the non-adolescent mothers, as was socioeconomic status (SES). SES is largely comprised of such variables as education, income, and occupation, thus making it difficult for the adolescent mother to have higher levels of SES.

Once again, the nature of the sample reflected another demographic difference in these two groups of mothers. The adolescent mothers were less likely to be married. Half of the non-adolescent mothers were married, whereas only one of the adolescent mothers 
was married. The adolescent mothers were also less likely to have more than one living child.

There were significant differences between the two groups with respect to racial identity. The adolescent sample had a higher proportion of Hispanic subjects than the non-adolescent mothers. The non-adolescent mothers had a higher proportion of Black participants as compared to the adolescent mothers.

There were significant differences between the two groups on dichotomous measures of prenatal history of use of alcohol and marijuana. A greater proportion of non-adolescent mothers reported use of alcohol during their pregnancy, whereas, a higher proportion of the adolescent mothers reported use of marijuana during pregnancy. There were no significant differences in the use of nicotine.

Although it was expected that there would be differences between the two groups on maternal demographics, it is encouraging that there were no differences between the two groups on any of the infant characteristics. This eliminated the possibility of differences being related to subtleties in infant medical status.

It was predicted that there would be a significantly greater proportion of infants with insecure attachments in the adolescent sample. The finding of no differences between the two groups with regards to attachment classification is consistent with one of the few studies that examined attachment, via the strange situation, in infants of adolescent mothers (Ward \& Carlson, 1995). The result of $67 \%$ security among the infants of the adolescent mothers is also consistent with normative data presented by Van Ijzendoorn and Kroonenberg (1988). This suggests that infants of adolescent mothers may resemble normative groups in prevalence of secure attachments to their mothers. 
What is particularly interesting is the drastic difference between the two groups on a number of self-reported maternal characteristics. The mothers in the adolescent group reported lower amounts of self-esteem than the mothers in the non-adolescent group on the Maternal Self Report Inventory. Essentially, these mothers have less confidence in the parenting role and less self-esteem as a mother as compared to their older counterparts. This finding is consistent with Hurlbut and colleagues (1997) who also found that adolescent self-esteem is lower than that of older mothers, although a different measure was used. Hurlbut and colleagues (1997) offer that self-esteem is a good indicator of an adolescent mother's parenting. It is a good indicator of her own developmental level and may reflect her own struggle with identity, which in turn affects her skills as a mother. Low self-esteem may lead the mother to have a poor view of the role of the child or to lack the knowledge of parenting skills (Hurlbut, et al., 1997). Additional findings by Hubbs-Tait, Osofsky, Hann, and Culp (1994) support this by suggesting that maternal self-esteem as well as maternal depression predict adolescent parenting. However, in this study no differences were found between the adolescent mothers and non-adolescent mothers on level of depression as measured by the Beck Depression Inventory.

When adolescent mothers were asked to rate whether they agreed or disagreed with statements of parenting stress, expectations of children, etc. on the CAPI, they endorsed stricter parenting attitudes indicative of potential for child abuse. These elevated findings can be discussed in reference to both adolescent and ethnic differences.

Adolescents tend to score higher on the CAPI (Milner, 1986; McCullough \& Scherman, 1998) These findings are consistent with reports of normative samples by Milner (1986). High school students (non parents) had an average rating of approximately 188 which is 
similar to the current finding. Also, adolescent mothers have been found to be more restrictive and punitive with their children than non-adolescent mothers (Garcia Coll, et al., 1986). Also, as mentioned before, adolescent mother's increased child abuse potential may be due to their lack of adequate knowledge of parenting and appropriate child behavior (McCullough \& Scherman, 1998) or living apart from related adults (Flanagan, et al., 1995).

Since the adolescent sample contained a large proportion of Hispanic youths, differences can be explained in terms of cultural attitudes toward parenting. Hispanic mothers when asked to assess the reasons for attachment behavior were more likely to focus on obedience and maintaining a proper demeanor than white anglo mothers (Harwood \& Miller, 1991), hence, the adolescents may reflect more stringent parenting beliefs.

In terms of quality of the attachment relationship, it has been hypothesized elsewhere that the Strange Situation may not be a good instrument for use in Hispanic or non-Anglo populations (Harwood, Miller, \& Irizarry, 1995). Although, in the current study, the majority of infants in the adolescent sample were classified as secure.

Differences in attachment were not found and attachment classifications were not different according to race. This is contrary to Broussard's (1995) finding that fewer black infants were classified as secure.

In order to address the issue that differences may be due to psychological characteristics of the child, a measure of maternal perception of infant's temperament and behavior was compared between the two samples. Although it has been found that teenage mothers have perceptions of their infant's temperament as more difficult than do 
older mothers (Field, et al., 1980), this finding was not supported in the current study. However, adolescent mothers rated their infants as having more activity than the ratings of activity level given by the non-adolescent mothers.

It has been shown that adolescent mothers may provide a less optimal home environment for their infants (Garcia Coll, et al., 1987). This was also confirmed in the present study. Roosa, et al. (1982) in their review of the literature, though limited at the time, found that SES and caretaking environment could be related to developmental problems for the children. More optimal SES, home environment, and maternal infant interaction were found among samples of older mothers (Roosa, et al.,1982). However, in this study only higher SES and more optimal home environments were found among the participants in the non-adolescent group.

In sum, the adolescent mothers have less self-esteem, more stress, stricter parenting attitudes, and provide a lower quality of the home environment than nonadolescent mothers. These mothers are also more likely to rate their infants as having a higher activity level than infants born to older mothers. Perhaps these data are reflecting the fact that over half of the non-adolescent mothers have had the experience of caring for another child, yet, it is still fascinating that these groups look so different on maternal psychosocial factors and these differences do not perturb the attachment relationship. Seifer and colleagues (1996) found no associations between a multiple risk index comprised of such factors as maternal psychopathology, maternal distress, poor quality of home environment, low SES and education, etc. and attachment classification.

It is encouraging that although theoretically, adolescent mothers are portrayed as disadvantaged in virtually every way possible, they do seem to be providing a relationship 
for their infant as one of availability and trust. Since the majority of the infants of adolescent mothers were securely attached, some other system may account for this finding. It is possible that the rate of security found in the infants of adolescent mothers is due to factors not measured here.

The unexpected finding of not being able to relate attachment insecurity to differences in maternal age, even when maternal psychosocial differences were so apparent, leads to a variety of questions. Each of the maternal characteristics measured have been related to adverse outcomes for children. This study may not have measured those particular outcomes. For example, adolescent parenting has been associated with lower cognitive functioning in their children at school age (Baldwin \& Cain, 1980).

Perhaps some other characteristic of the mother or child has buffered the child against the adversity associated with low SES, poor home environment, low maternal selfesteem, etc. Although the adolescent mothers reported higher levels of parenting stress, the family's living situation or level of perceived social support could be a buffer or protective factor for the child and thus the attachment relationship. However, these two factors were not measured in the current study.

It is also possible that the maternal psychosocial factors measured here may not reflect parenting competence of adolescent mothers. Shapiro and Mangelsdorf (1994) suggest that adult models of parenting competence may not accurately describe the factors that foster or inhibit parenting competence among adolescent mothers. For instance, they found results that seem to be at odds with the notion that parenting competence is positively associated with social support and well being and inversely related to perceived stress. Specifically, adolescent mothers who perceived high support from the baby's 
father had higher self esteem and felt more efficacious. Yet, the more support they perceived, the less competent they were in terms of their overall expressivity (Shapiro \& Mangelsdorf, 1994). Moreover, Rauch-Elnekave (1994) postulate adolescent mothers may experience difficulties in school and that early motherhood may be a way for them to experience success.

Attachment theory is believed to purport that the infant's experiences prior to the Strange Situation do correlate in a predictable and consistent manner to attachment behavior (Lamb, Thompson, Gardner, \& Charnov, 1985). Mothers who behave sensitively to their infants tend to have securely attached infants (Ainsworth, et al., 1978). Mothers who deviate from this are more likely to have insecurely attached infants. Factors associated with insecurity were present among the adolescent sample yet, they did not seem to influence the incidence of insecurity. The data do not seem to reflect the theoretical underpinnings of attachment.

Observational measures of infant characteristics were not used in the current study, hence, one can not rule out the role they may play in describing the mother-infant relationship. Since most temperament questionnaires include items that ask the parent to rate the child's behavior in the context of parent-child interactions (Vaughn, et al., 1992), it may be advantageous to include an objective observational measure of temperament or parent-child interaction and examine their relationship to attachment security. Future studies should attempt to examine this in the context of those variables presented here.

The findings of the present study may be related to the larger environmental context of these dyads. For example, the level of parenting stress, social support, developmental level of the mother, knowledge of child development, race, ethnicity, drug 
use, and socioeconomic status may contribute to some of the findings herein. The difference in drug use between the two groups may have contributed to the results seen, although the measure of drug use did not take into account the frequency, amount, or timing of exposure. Future investigations should examine this further.

Some other limitations include the fact that measures of the adolescent mother's developmental level and knowledge of child development were not included, so, it is difficult to conclude that these may have been related to the results. Flanagan (1998) challenges the notion that adolescent parenting is associated with adversity and purports that the developmental process may impact the mothering experience of adolescents. Here, is where interventions should be targeted (Flanagan, 1998). Future research should include these factors, as well as, measures of social support and examinations of the larger caregiving environment, to determine the impact they may have on the quality of parenting provided by adolescent mothers and the quality of the attachment relationship between adolescent mothers and their infants. 


\section{References}

Abidin, R. (1983). The Parenting Stress Index - Manual. Virginia: Pediatric Psychology Press.

Ainsworth, M. (1984). Attachment. In N. Endler \& J. McV. Hunt (Eds.), Personality and the Behavioral Disorders, 1. New York: Wiley.

Ainsworth, M., Blehar, M., Waters, E., \& Wall, S. (1978). Patterns of attachment: A psychological study of the strange situation. Hillsdale, NJ: Erlbaum.

Ainsworth, M., \& Witting, B. (1969). Attachment and exploratory behavior of one-year-olds in a strange situation. In B. Foss (Ed.), Determinants of Infant Behavior. London: Methuen.

Baldwin, W., \& Cain, V. (1980). The children of teenage parents. Family Planning Perspectives, 12, 34-43.

Barratt, M., \& Roach, M. (1995). Early interactive processes: Parenting by adolescent and adult single mothers. Infant Behavior and Development, 18, 97-109.

Beck, A., Steer, R., \& Garbin, M. (1988). Psychometric properties of the beck depression inventory: Twenty five years of evaluation. Clinical Psychology Review, 8 , $77-100$.

Beck, A., Ward, C., Mendelson, M., Mock, J., \& Erbaugh, J. (1961). An inventory for measuring depression. Archives of General Psychiatry, 4, 561-571.

Becker, P. (1987). Sensitivity to infant development and behavior: A comparison of adolescent and adult single mothers: Research in Nursing Health, 10, 119-127.

Belsky, J., Rovine, M., \& Taylor, D. (1984). The Pennsylvania Infant and Family Development Project, 3: The origins of individual differences in infant-mother attachment: Maternal and infant contributions. Child Development, 55, 718-728. Books.

Bowlby, J. (1969). Attachment and loss: Vol. 1. Attachment. New York: Basic

Broussard, E. (1995). Infant attachment in a sample of adolescent mothers. Child Psychiatry and Human Development, 25, 211-219.

Caldwell, B., \& Bradley, R. (1984). Administration manual (revised edition): Home observation for measurement of the environment. Little Rock: University of Arkansas. 
Cicchetti, D. (1987). Developmental psychopathology in infancy: Illustration from the study of maltreated youngsters. Journal of Consulting and Clinical Psychology, $\underline{55}, 837-845$.

Cohen, J. (1988). Statistical Power Analysis: A computer program. New York.

Crittenden, P. (1985). Maltreated infants: Vulnerability and resilience. Journal of Child Psychology and Psychiatry, 26, 85-96.

Culp, R., Appelbaum, M., Osofsky, J., \& Levy, J. (1988). Adolescent and older mothers: Comparison between prenatal maternal variables and newborn interaction measures. Infant Behavior and Development, 11, 353-362.

DeLissovoy, V. (1973). Child care by adolescent parents. Children Today, 35, $22-25$.

Desrogatis, L. (1993). Brief Symptom Inventory (BSI): Administration, Scoring, and Procedures Manual, Third Edition. Minneapolis, MN: National Computer Systems, Inc.

Egeland, B., \& Farber, E. (1984). Infant-mother attachment: Factors related to its development and changes over time. Child Development, 55, 753-771.

Egeland, B., \& Sroufe, L. A. (1981). Attachment and early maltreatment. Child Development, 52, 44-52.

Elster, A., McAnarney, E., \& Lamb, M. (1983). Parental behavior of adolescent mothers. Pediatrics, 71, 494-503.

Erickson, M., Sroufe, A., \& Egeland, B. (1985). The relationship between quality of attachment and behavior problems in a preschool high risk sample. In I. Bretherton \& E. Waters (Eds.), Growing points of attachment theory and research. Monographs of the Society for Research in Child Development, 50 (1-2, Serial No. 209).

Field, T. (1980). Interactions of preterm and term infants with their lower and middle class teenage and adult mothers. In T. Field, S. Goldberg, D. Stern, \& A. Sostek (Eds.), High Risk Infants and Children: Adult and Peer Interactions. New York: Academic.

Field, T., Widmayer, S., Stringer, S., \& Ignatoff, E. (1980). Teenage, lower class, black mothers and their pre-term infants: An intervention and developmental follow-up. Child Development, 51, 426-436. 
Flanagan, P. (1998). Teen mothers: Countering the myths of dysfunction and developmental disruption. In C. Garcia Coll, J. Surrey, (Eds.), Mothering Against the Odds: Diverse Voices of Contemporary Mothers. New York: Guilford.

Flanagan, P., Coppa, D., Riggs, S., \& Alario, A. (1994). Communication behaviors of infants of teen mothers: An exploratory study. Journal of Adolescent Health, 15, 169-175.

Flanagan, P., Garcia Coll, C., Andreozzi, L., \& Riggs, S. (1995). Predicting maltreatment of children of teenage mothers. Archives of Pediatric Adolescent Medicine $149,451-455$.

Frodi, A., Grolnick, W., Bridges, L., \& Berko, J. (1990). Infants of adolescent and adult mothers: Two indices of socioemotional development. Adolescence, 98,363 374 .

Furstenberg, F., Brooks-Gunn, J., \& Morgan, S. (1987). Adolescent mothers and their children later in life. Family Planning Perspectives, 19, 142-151.

Garcia Coll, C., Hoffman, J., \& Oh, W. (1987). The social ecology and early parenting of caucasian adolescent mothers. Child Development, 58, 955-963.

Garcia Coll, C., Vohr, B., Hoffman, J., \& Oh, W. (1986). Maternal and environmental factors affecting developmental outcome of infants of adolescent mothers. Developmental and Behavioral Pediatrics, 7, 230-236.

Grossmann, K., Grossmann, K., Spangler, G., Suess, G., \& Unzner, L. (1985). Maternal sensitivity and newborn's orientation responses as related to quality of attachment in northern Germany. In I. Bretherton \& E. Waters (Eds.), Growing points of attachment theory and research. Monographs of the Society for Research in Child Development, 50 (1-2, Serial No. 209).

Harwood, R. \& Miller, J. (1991). Perceptions of attachment behavior: A comparison of anglo and puerto rican mothers. Merrill Palmer Quarterly, 37, 583-599.

Harwood, R., Miller, J., \& Irizarry, N. (1995). Culture and Attachment: Perceptions of the Child in Context. New York: Guilford.

Hollingshead, A. (1975). Four Factor Index of Social Status. New Haven, CT: Yale University, Department of Sociology.

Hubbs-Tait, L., Osofsky, J., Hann, D., \& Culp, A. (1994). Predicting behavior problems and social competence in children of adolescent mothers. Family Relations, 43, 439-446. 
Hurlbut, N., Culp, A., Jambunathan, S., \& Butler, P. (1997). Adolescent mother's self esteem and role identity and their relationship to parenting skills knowledge. Adolescence, 32, 639-655.

Jones, F., Green, V., \& Krauss, D. (1980). Maternal responsiveness of primiparous mothers during the postpartum period: Age differences. Pediatrics, 65, 579584.

Lamb, M., Hopps, K., \& Elster, A. (1987). Strange situation behavior of infants with adolescent mothers. Infant Behavior and Development, 10, 39-48.

Lamb, M., Thompson, R., Gardner, W., \& Charnov, E. (Eds.). (1985). InfantMother Attachment: The Origins and Developmental Significance of Individual Differences in Strange Situation Behavior. New Jersey: Erlbaum.

Lawrence, R., McAnarney, E., Aten, M., Iker, H., Baldwin, C., \& Baldwin, A. (1981). Aggressive behaviors in young mothers: Markers of future morbidity? Pediatric Research, 15, 443.

Levine, L., Garcia Coll, C., \& Oh, W. (1985). Determinants of mother-infant interaction in adolescent mothers. Pediatrics, 75, 23-29.

Main, M., \& Cassidy, J. (1988). Categories of response to reunion with the parent at age six: Predictable from infant attachment classification and stable over a onemonth period. Developmental Psychology, 24, 415-426.

Main, M., \& Solomon, J. (1990). Procedures for identifying infants as disorganized-disoriented during the Ainsworth Strange Situation. In M. Greenberg, D. Cicchetti, \& E.M. Cummings (Eds.), Attachment in the preschool years: Theory, research, and intervention (pp. 121-160). Chicago: University of Chicago Press.

McAnarney, E., Lawrence, R., \& Atens, M. (1979). Premature parenthood a preliminary report of adolescent mothers and behavioral characteristics of their first born infants. Pediatric Research, 13, 328.

McCullough, M., \& Scherman, A. (1991). Adolescent pregnancy: Contributing factors and strategies for prevention. Adolescence, 26, 809-816.

Miller, S. (1984). The relationship between adolescent childbearing and child maltreatment. Child Welfare, 63, 553-557.

Milner, J. (1980). The Child Abuse Potential Inventory manual (second edition). Illinois: Psytec. 
Parks, P., \& Arndt, E. (1990). Differences between adolescent and adult mothers of infants. Journal of Adolescent Health Care, 11, 248-253.

Radke-Yarrow, M., Cummings, E., Kuczynski, L., \& Chapman, M. (1985). Patterns of attachment in two and three year olds in normal families and families with parental depression. Child Development, 56, 884-893.

Ragozin, A., Basham, R., Crnic, K., Greenberg, M., \& Robinson, N. (1982). Effects of maternal age on parenting role. Developmental Psychology, 18, 627-634.

Rauch-Elnekave, H. (1994). Teenage motherhood: its relationship to undetected learning problems. Adolescence, 29, 91-104.

Roosa, M., Fitzgerald, H., \& Carlson, N. (1982). Teenage parenting and child development: A literature review. Infant Mental Health Journal, 3 , 4-18.

Roosa, M, \& Vaughan, L. (1984). A comparison of teenage and older mothers with preschool children. Family Relations, 33, 259-265.

Rothbart, M. (1981). Measurement of temperament in infancy. Child Development, 52, 569-578.

Sandler, H., Vietze, P., \& O'Connor, S. (1981). Obstetric and neonatal outcomes following intervention with pregnant teenagers. In K. Scott, T. Field, \& E. Robertson (Eds.), Teenage parents and their offspring. New York: Grune \& Stratton.

Schneider_Rosen, K., \& Cicchetti, D. (1984). The relationship between affect and cognition in maltreated infants: Quality of attachment and the development of visual self recognition. Child Development, 55, 648-658.

Seifer, R., \& Dickstein, S. (1993). Parental mental illness and infant development. In C. Zeanah (Ed.), Handbook of Infant Mental Health (pp. 120-142). New York: Guilford.

Seifer, R., Sameroff, A., Dickstein, S., Keitner, G., Miller, I., Rasmussen, S., \& Hayden, L. (1996). Parental psychopathology, multiple contextual risks, and one year outcomes in children. Journal of Clinical Child Psychology, 25, 423-435.

Seifer, R., \& Schiller, M. (1995). The role of parenting sensitivity, infant temperament, and dyadic interaction in attachment theory and assessment. In $\mathrm{E}$. Waters, B. E. Vaughn, G. Posada, \& K. Kondo-Ikemura (Eds.), Caregiving, cultural, and cognitive perspectives on secure base behavior and working models: New growing points of attachment theory and research. Monographs of the Society for Research in Child Development, 60 (Serial No. 244, pp. 146-174). 
Shapiro, J. \& Mangelsdorf, S. (1994). The determinants of parenting competence in adolescent mothers. Journal of Youth and Adolescence, 23, 621-642.

Shea \& Tronick, E. (1984). The Maternal Self-Report Inventory: A research and clinical instrument for assessing maternal self esteem. In H. Fitzgerald, B. Lester, \& M. Yogman, (Eds.), Theory and Research in Behavioral Pediatrics. Boston: Plenum.

Spieker, S., \& Booth, C. (1988). Maternal antecedents of attachment quality. In J. Belsky \& T. Nezworski (Eds.), Clinical implications of attachment (pp. 300-323). Hillsdale, NJ: Erlbaum.

Teti, D., Gelfand, D., Messinger, D., \& Isabella, R. (1995). Maternal depression and the quality of early attachment: An examination of infants, preschoolers, and their mothers. Developmental Psychology, 31, 364-376.

Thompson, R., Lamb, M., \& Estes, D. (1982). Stability of infant-mother attachment and its relationship to changing life circumstances in an unselected middle class sample. Child Development, 53, 144-148.

Tronick, E. Z., Ricks, M., \& Cohn, J. (1982). Maternal and infant affective exchange: Patterns of adaptation. In T. Field \& A. Fogel (Eds.), Emotion and Early Interaction. Hillsdale, $\mathrm{NJ}$ : Erlbaum.

Turner, P. (1991). Relationship between attachment, gender, and behavior with peers in preschoolers. Child Development, 62, 1475-1488.

Van Ijzendoorn, M., Goldberg, S., Kroonenberg, P., \& Frenkel, O. (1992). The relative effects of maternal and child problems on the quality of attachment: A metaanalysis of attachment in clinical samples. Child Development, 63, 840-858.

Van Ijzendoorn, M., \& Kroonenberg, P. (1988). Cross cultural patterns of attachment: A meta-analysis of the strange situation. Child Development, 59, 147-156.

Vaughn, B., Egeland, B., Sroufe, L. A., \& Waters, E. (1979). Individual differences in infant-mother attachment at twelve and eighteen months: Stability and change in families under stress. Child Development, 50, 971-975.

Vaughn, B., Lefever, G., Seifer, R., \& Barglow, P. (1989). Attachment behavior, attachment security, and temperament during infancy. Child Development, 60, 728-737.

Vaughn, B., Stevenson-Hinde, J., Waters, E., Kotsaftis, A., Lefever, G., Shouldice, A., Trudel, M., \& Belsky, J. (1992). Attachment security and temperament in infancy and early childhood: Some conceptual clarifications. Developmental Psychology, $\underline{28}, 463-473$. 
Ward, M., \& Carlson, E. (1995). Associations among adult attachment representations, maternal sensitivity, and infant mother attachment in a sample of adolescent mothers. Child Development, 66, 69-79.

Waters, E. (1978). The reliability and stability of individual differences in infantmother attachment. Child Development, 49, 483-494.

Whitman, T., Borkowski, J., Schellenbach, C., \& Nath, P. (1987). Predicting and understanding developmental delay of children of adolescent mothers: A multidimensional approach. American Journal of Mental Deficiency, 92, 40-56.

Zuravin, S. (1988). Child maltreatment and teenage first births: A relationship mediated by chronic sociodemographic stress? American Journal of Orthopsychiatry, 58, 91-103. 
Appendix A

Strange Situation Scoring Worksheet 


\section{Strange Situation Scoring Worksheet}

ID: $\square \square \square \square \square$

Rater: $\square \square \square \square$

Episode 2: Mother-Child

Episode 3: Stranger Enters

Episode 4: $1^{\text {st }}$ Separation

Episode 5: $1^{\text {st }}$ Reunion

Proximity Seeking $\square$ Contact Maintenance $\square \quad$ Avoidance $\square \quad$ Resistance $\square$ Episode 6.7: $2^{\text {nd }}$ Separation / Stranger Reunion

Episode 8: $2^{\text {nd }}$ Reunion

Proximity Seeking $\square$ Contact Maintenance $\square \quad$ Avoidance $\square \quad$ Resistance $\square$ 
Appendix B

\section{MLS Form for HOME}




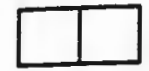

Cater Number

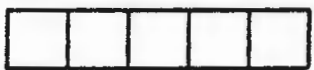

Screaning Number

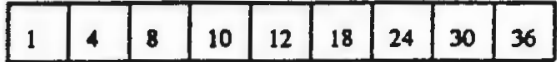

Visit Mooth

Birth Nurober

\section{NEW HOME OBSERVATION FOR MEASUREMENT OF ENVIRONMENT}

Record whecher the bebuvior or ovects dewcribed in each itecr are obeerved during the visit or reported by the pareat or carotaker $s$ characterietic of the bom eovirooment.

- These items may require direct questions.

\section{Part I. EMOTIONAL AND VERBAL RESPONSTVITY OF MOTHER/CARETAKER}

1. Ceretaker spontaneoushy vocalizes to child al least twice during visit (exchuding coolding).

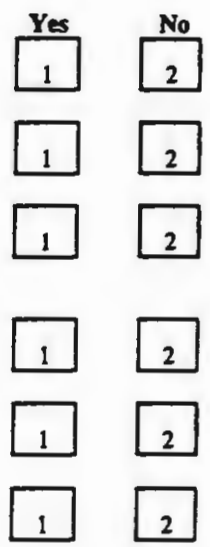

6. Carectaker exproseces ideas freely and earily and uses statements of appropriate length for conversations (e.g., gives more then brief enswers).

-7. Carecker permits child accesionelly to eagage in "messy" types of piay.

8. Caretaker spontenoously praises the child's qualitise or behavior twice during visit.

9. When speaking of or to child, cartaker's voice conveys positive feeling.

10. Carouker caresses or bisses child at least once during visit.

11. Ceretuker shows come pasitive emotioan responses to praice of child offored by visitor.

12. Caretaker makes eye to eye contuct with child.

13. Carecaker cooveys positive affect son-verbally toward child. 


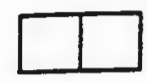

Cencer Number

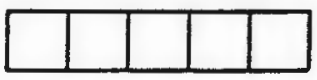

Screening Number

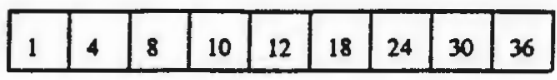

Visit Mooch
Page 2 of 5

Birth Number

Part II. AVOIDANCE OF RESTRICTION AND PUNTSHMENT

14. Carotaker does bot shoul at child during visit.

15. Carouker does not express overt ennoyance with or houtility toward child.

16. Carechker soither sleps sor spanles child during visit.

-17. Carecaker reports that $n$ more then one instanco of physical punishmeot occurred during the past wook.

18. Cerecter does not scold or derogale child during visit.

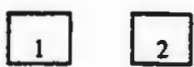

19. Caretaker does not interfere with child's actions or restrict child's movements more then 3 timer during my visit.

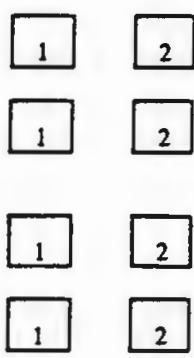

21. Family hes a pet.

Yes $\frac{\text { No }}{1} \quad 2$

22. When carecaker is awny, care is provided by one of throe rogular substitates.

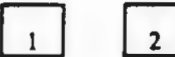

23. Someone tukes child into grocery store at least once a week.

24. Child gots our of bouse at best four times a week.

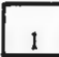

25. Child is taken regularly to doctor's office or clinic.

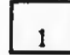

26. Child has a special place in which to keep hisher toys and "treasures".

27. Child's play eovironment appeass safe and free of hazands.

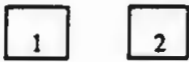

28. Home exvironmeot sppears clean.

29. Child has a fooding schoctule.

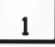




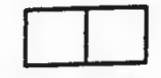

Center Number

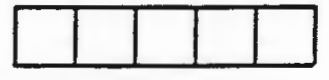

Screaning Number

\begin{tabular}{|l|l|l|l|l|l|l|l|l|}
\hline 1 & 4 & 8 & 10 & 12 & 18 & 24 & 30 & 36 \\
\hline
\end{tabular}

Visit Month

Birtb Number

Part III. ORGANIZATION OF ENVIRONMENT (continued)

30. Meals are pianned and provided at roguler times for family mocobers.

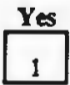

No

31. Child bas a safe, consister place to sleep (e.g. crib, bessinet, play pen).

32. Each member of the family regularly sleeps in a epecific pleco.

33. Family has regular and appropriate morning routine.

-34. There are auficied raples for childreo.

35. Child and child's clothing eppear clown.

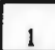

36. Caretaker hes not made more than two moves in the past 2 years.

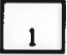

\section{Part IV. PROVISION OF APPROPRLATE PLAY MATERIAL}

37. Child bes come muscle activity toys or equipment.

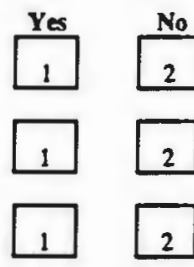

39. Child hes atroller or walker, kiddie car, scooter or tricycle.

40. Canaker provides toys or interesting activities for child churing interview.

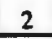

41. Provide learning equipmeat approprivte to age - cuddly toy or role plinying toys."

42. Provides learning equipment approprinte to age - mobile, thble and chairs, high chair, play peo.

43. Provider eye-band coordination toys - items to go in and out of receptacle, fit togabor toys, boads. 


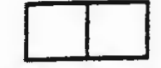

Ceoter Number

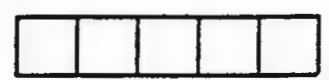

Screening Number

\begin{tabular}{|l|l|l|l|l|l|l|l|l|}
\hline 1 & 4 & 8 & 10 & 12 & 18 & 24 & 30 & 36 \\
\hline
\end{tabular}

Visit Modeb

Birth Number

Part IV. PROVISION OF APPROPRIATE PLAY MATERIAL (continued)

44. Provides oyo-hand coordination toys thet permit combinations - atecking or posting toys, blocks or building toys.
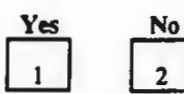

45. Provides toys for literature and massic.

\section{Part V. MATERNALCARETAKER INVOLVEMENT WTTH CHILD}

46. Cartaker loads to keep child withio visul nange and to look at him/her often.

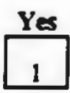

47. Caretuker "tullks" to child while doing ber work.

48. Carecaker consciously encourages developmental advance.

49. Carokaker inveats "meturing toys" with vahue via ber attontion.

50. Caretaker structures child's play periods.

51. Caretaker provides toys that challenge child to develop new akills.

52. Older children are not bandling child in inappropriate fashion.

53. The child is $\mathrm{nxt}$ lof alone or loft in the care of ocher childrea lass then 12 years of age.

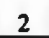

-54. Child is not regularly carod for by other childrea in place of the carocaker.

-55. Child is not allowed to food self.

56. Cerotaker picks up child reguierly when not sloeping.

Part VI. OPPORTUNTTIES FOR VARIETY IN DARY STMMULATION

57. Fucher (or Caretaker's partber) provides wouse carouking overy day.

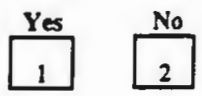

58. Carecaker reads stories at lonst throe times weekly. 


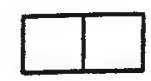

Conter Number

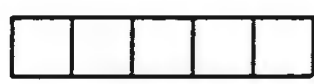

Screoning Number

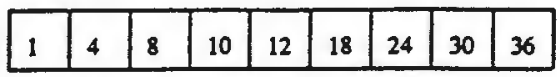

Visit Mooth

Birth Number

\section{Part VI. OPPORTUNTTIES FOR VARIETY IN DAIIY STMMULATION (continued)}

59. Child outs a beat oos mad per day with carctaker and partmor (opposite nex).

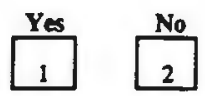

60. Child outs at least one meal per day with caretaker.

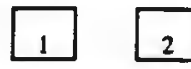

61. Fanily visits or receives visits from relative (approximately onces a month).

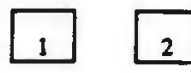

62. Child hes three or more books of his/her own.

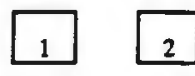

63. Reading meterial is present and visible.

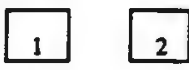

64. Home appears well lit.

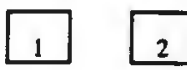

65. Tolevision is not on during most of visit.

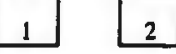

Form completed by:

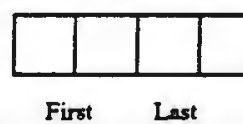

Dale form completed:

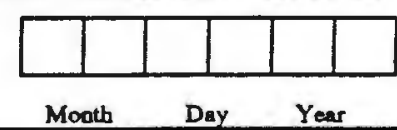


Appendix C

MLS Form for PSI 


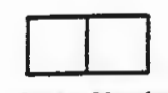

Center Number

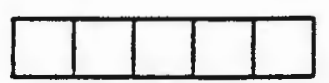

Screening Number

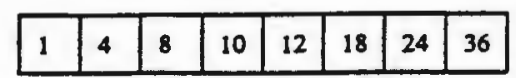

Visit Month

\section{PARENTING STRESS INDEX (PSI)}

\section{Directions:}

In answering the following questions, please think about the the child you brought in today for the study visit. I am going to read some statements to you. Using this scale I want you to tell me bow close the ratements are to bow you feel.

In other words if your feelings about the statemeat are:

"Yes, that's certainly bow I feel" then your choice would be (1) Strongly Agree.

"Yes, that's how I feel sometimes" then your choice would be (2) Agree.

"I'm not sure bow I feel" then your choice would be (3) Not Sure.

"No, I don't usually feel that way" then your choice would be (4) Disagree.

"No, I don't feel that way at all" then your choice would be (5) Strongly Disagree.

While you may not find an answer which exactly states your feelings, please choose the answer which comes closest to describing bow you feel.

\section{YOUR FIRST REACTION TO EACH OUESTION SHOULD BE YOUR ANSWER.}

Start with an example (SEE SCRPT)
(1)
(2)
(3)
(4)
(5)
Strongly Agree
Agree
Not Sure
Disagree
(Not usually)

Birth Number

1. You often have the feeling that you canot bandle problems very well.

$\begin{array}{lllll}1 & 2 & 3 & 4 & 5 \\ 1 & 2 & 3 & 4 & 5 \\ 1 & 2 & 3 & 4 & 5 \\ 1 & 2 & 3 & 4 & 5 \\ 1 & 2 & 3 & 4 & 5 \\ 1 & 2 & 3 & 4 & 5 \\ 1 & 2 & 3 & 4 & 5 \\ 1 & 2 & 3 & 4 & 5\end{array}$




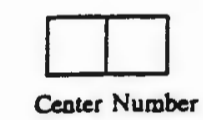

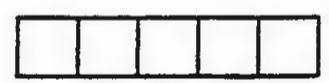

Screening Number

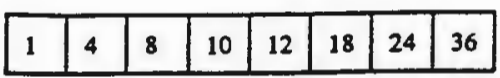

Visit Month

Birth Number

Strongly Agree 1

$\begin{array}{cc}\text { Agree } & \text { Not Sure } \\ 2 & 3\end{array}$
3

Disegree

\section{Strongly Disagree} 5

9. You feel alone and without friends.

10. When you go to a party you usually think that you won't eajoy yourself.

11. You are not as interested in people as you used to be.

12. You doa't enjoy things as you used to.

13. This child hardly ever does things that make you feel good.

14. Most times you feel that this child does not like you and does not want to be close to you.

15. This ebild smiles at you much less than you expected.

16. When you do things for this child you get the feeling that $s$ he doesn't notice or appreciate them.

17. Whes playing, s/he doesn't often giggle or laugh.

18. This child doeso't seem to learn as quickly as most children.

19. This child doesn't seem to smile as much as most childrea.

20. This child is not able to do as mueh as you expected.

21. It takes a long time and it is very bard for this child to get used to new things.

$\begin{array}{lllll}1 & 2 & 3 & 4 & 5 \\ 1 & 2 & 3 & 4 & 5 \\ 1 & 2 & 3 & 4 & 5 \\ 1 & 2 & 3 & 4 & 5 \\ 1 & 2 & 3 & 4 & 5 \\ 1 & 2 & 3 & 4 & 5 \\ 1 & 2 & 3 & 4 & 5 \\ 1 & 2 & 3 & 4 & 5 \\ 1 & 2 & 3 & 4 & 5 \\ 1 & 2 & 3 & 4 & 5 \\ 1 & 2 & 3 & 4 & 5 \\ 1 & 2 & 3 & 4 & 5 \\ 1 & 2 & 3 & 4 & 5\end{array}$

22. You feel that you are:

1. not very good at being a pareat,

(Use a written card

2. a person who has some trouble being a pareat,

for the mother $t$

3. an average parent.

choose.)

4. Getter then average pareat,

5. a very good pareat.

23. You are bothered by not baving closer and warmer feelings for this child.

24. Sometimes this child does things that botber you, just to be bad.

25. This child seems to cry or fuss more often than most childrea.

26. This child generally wakes up in a bad mood.

27. You feel that s/he is very moody and ensily upset.

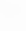

(n)

s




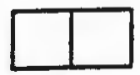

Center Number

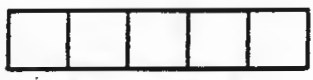

Screening Number

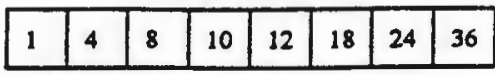

Visit Month

Birth Number

\begin{tabular}{|ccccc|}
\hline Strongly Agree & Agree & Not Sure & Disagree & Strangly Disagree \\
1 & 2 & 3 & 4 & 5 \\
\hline
\end{tabular}

28. This child does a fow things which bother you a great deal.

29. This child reacts very strongly when eomething bappens that s/he doeso't like.

$\begin{array}{lllll}1 & 2 & 3 & 4 & 5 \\ 1 & 2 & 3 & 4 & 5 \\ 1 & 2 & 3 & 4 & 5 \\ 1 & 2 & 3 & 4 & 5\end{array}$

32. You bave found that getting this child to do something or stop doing something is: 1. much berder then you expected,

2. somewbat barder than you expecied,

3. about as bard as you expected,

(Use card) 4. somewhat easier than you expected,

5. much easies than you expected.

33. Thiak carefully and count the number of things that this child does that bother you. For example, whines, cries, interrupts, fights, elc. Please tell me the number you counted.
1. $10+$
2. 8-9
3. 6-7
4. 4-5
5. $0-3$

1

$\begin{array}{llll}2 & 3 & 4 & 5\end{array}$

34. There are some things this child does that really bother you a lot.

35. This child urned out to be more of a problem then you had expected.

36. This child makes more demands on you than most children would.

$\begin{array}{lllll}1 & 2 & 3 & 4 & 5 \\ 1 & 2 & 3 & 4 & 5 \\ 1 & 2 & 3 & 4 & 5 \\ 1 & 2 & 3 & 4 & 5\end{array}$

Interviewer Response:

37. Rate bow confideat you feel that information reported on this form is relinble and truthful.

Not Confident

1

Somewhat Confideat

2
Very Confident

3

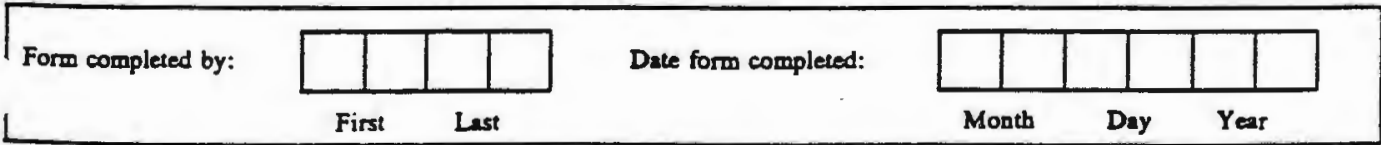


Appendix D

MLS form for CAPI 


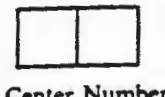

Center Number

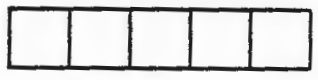

Screening Number

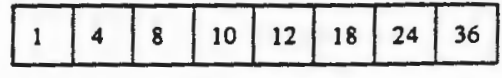

Visit Montb

Birtb Number

\section{CAP INVENTORY FORM VI}

Interviewer: The items should be read aloud without explanation, advice, or comment. If the respondent asks questions about the meaning of any item, explain tbat you are interested io her interpretation and repeat the statement emphasizing such words as "never, sometimes, always, often, etc." which can help to define the answers. Statements which refer to "your child" refer wo the study child, you may need to clarify this for the respondent.

I an going to read you a list of stotements expressing how you might feel about many different manters. Please listen carefully and tell me whether you agree or disagree with the starement.

1. You never feel somy for others

2. You enjoy baving pets

3. You bave ciways been strong and healthy

4. You like most people

5. You are a confused person

6. You do aot trust most people

7. People expect too much from you

8. Children should never be bad

9. You are often mixed up

10. Spanking that only bruises a cbild is okay

11. You always try to check on your child when he/she is crying

12. You sometimes act without thinking

13. You cannot depend on others

14. You are a happy persoo

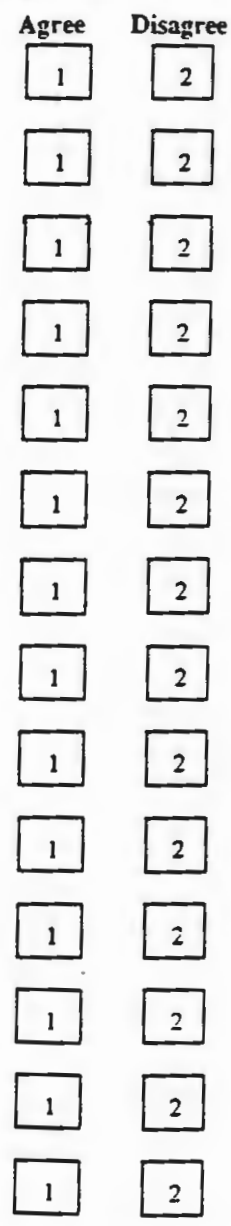




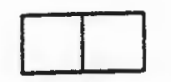

Center Number

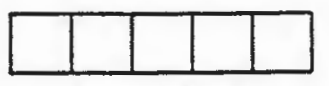

Screening Number

\begin{tabular}{|l|l|l|l|l|l|l|l|}
\hline 1 & 4 & 8 & 10 & 12 & 18 & 24 & 36 \\
\hline
\end{tabular}

Visit Montb
Birth Number
15. You like to do things with your family

16. Teenage girls need to be protected

17. You are often angry inside

18. Sometimes you feel all alone in the world

19. Everything in a bome should always be in its place

20. You sometimes worry that you cannot meet the needs of a child

21. Knives are dangerous for children

22. You ofien feel rejected

23. You are ofteo lonely irside

24. Little boys should never learn sissy games

25. You often feel very frustrated

26. Children should never disobey

27. You love all childrea

28. Sometimes you feat that you will lose coatrol of yourself

29. You sometimes wish that your father would have loved you more

30. You bave a child who is clumsy

31. You know what is the right and wrong way to act

32. Your telephone aumber is unlisted

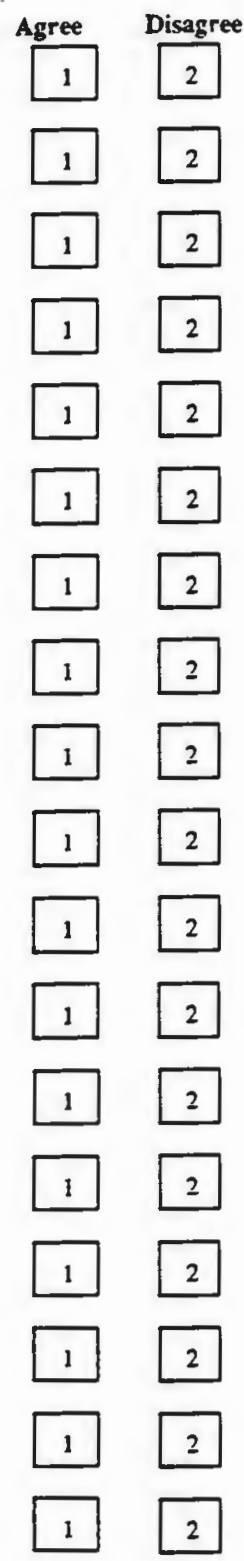




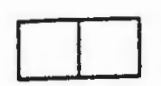

Center Number

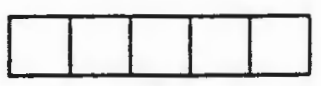

Screening Number

\begin{tabular}{|l|l|l|l|l|l|l|l|}
\hline 1 & 4 & 8 & 10 & 12 & 18 & 24 & 36 \\
\hline
\end{tabular}

Visit Month

Birth Number

33. The birb of a child will usually cause problems in a marriage

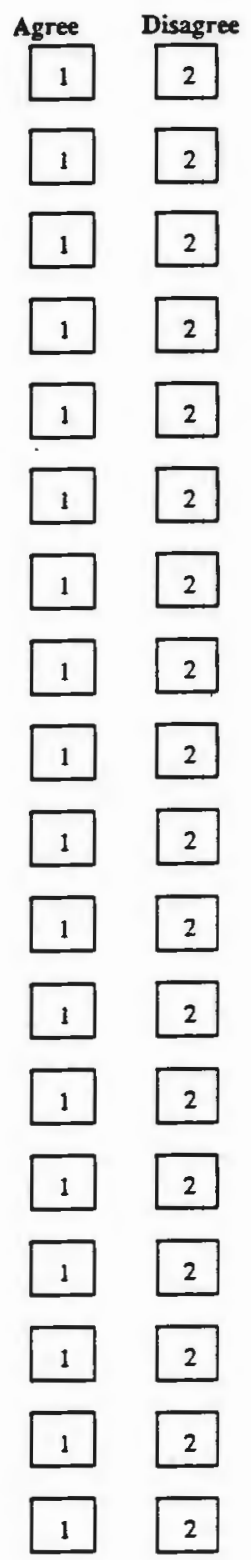

50. Children are really little adults 


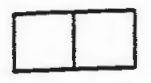

Center Number

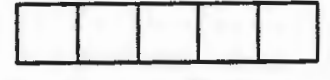

Screening Number

\begin{tabular}{|l|l|l|l|l|l|l|l|}
\hline 1 & 4 & 8 & 10 & 12 & 18 & 24 & 36 \\
\hline
\end{tabular}

Birh Number

51. You bave a child who breaks things

52. You often feel worried

53. It is okay to let a child stay in dirty diapers for a while

54. A ehild should never talk back

55. Sometimes your behavior is childisb

56. You are ofien easily upset

57. Sometimes you have bad thoughts

58. Everyone must think of himseif first

59. A crying child will never be bappy

60. You have never bated anotber person

61. Children should not learn bow to swim

62. You always do what is right

63. You are often worried inside

64. You bave a child who is sick a lot

65. Sometimes you do not like the way you act

66. You sometimes fail to keep all of your promises

67. People have caused you a lot of pain

68. Childreo should stay clean

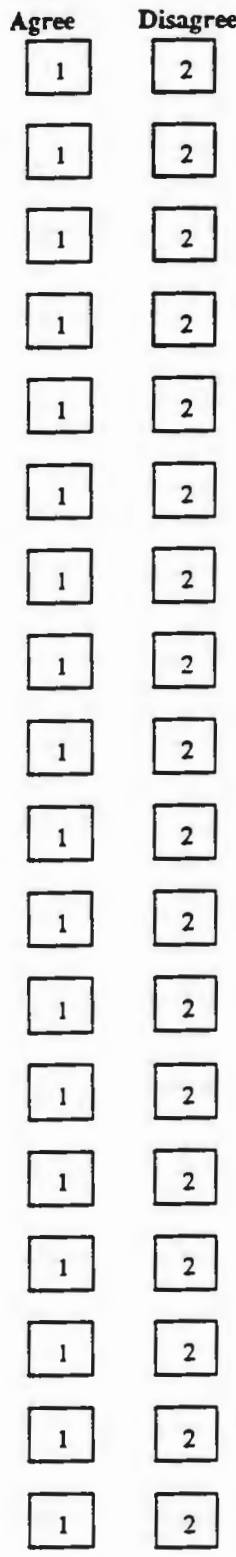




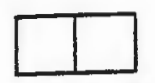

Center Number

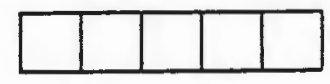

Screening Number

\begin{tabular}{|l|l|l|l|l|l|l|l|}
\hline 1 & 4 & 8 & 10 & 12 & 18 & 24 & 36 \\
\hline
\end{tabular}

Visit Month

Birtb Number

69. You have a child who gets into trouble a lot

70. You never get mad at others

71. You always get along with others

72. You often think about what to do

73. You find it hard to relax

74. These days a person doesn' $t$ really know' on whom one can count

75. Your life is bappy

76. You have a physical handicap

77. Children should bave play clothes and good clothes

78. Other people do oot understand bow you feel

79. A five year old who wets his bed is bad

80. Children should be quiet and listen

81. You have several close frieads in your neighborbood

82. It is the school's responsibility to educate the child

83. Your family fights a lot

84. You bave headaches

85. As a child you were abused

86. Spanking is the best punishment

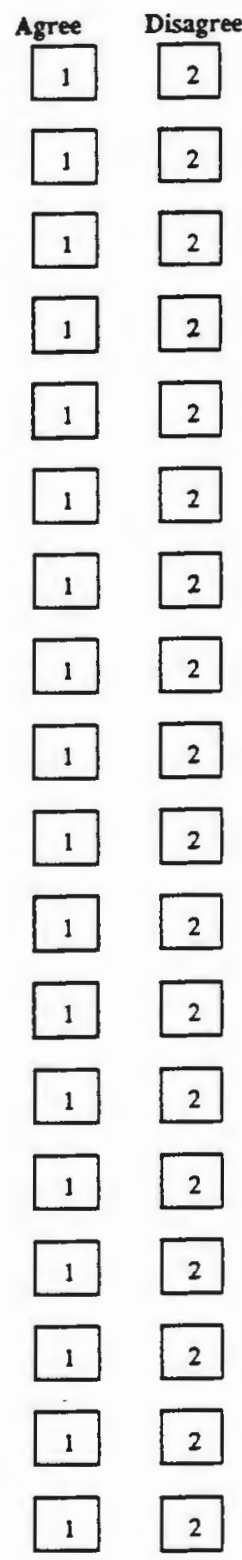



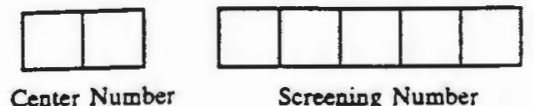

Sereening Number

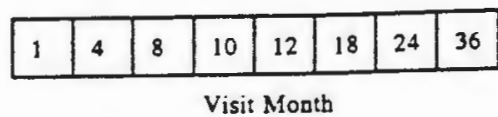

Visit Month
Birtb Number
87. You do not like to be touched by others

88. People who ask for belp are weak

89. Children should be washed before bed

90. You do not laugh very much

91. You have several close frieods

92. People should take care of their own needs

93. You bave fears go one knows about

94. Your family has problems getting along

95. Life often seems useless to you

96. A child should be potty trained by the time be's one year old

97. A child in a mud puddle is a bappy sight

98. People do not understand you

99. You ofien feel worhless

100. Other people bave made your life unhappy

101. You are always a kind person

102. Sometimes you do not know why you act as you do

103. You bave many personal problems

104. You bave a child who ofter burts himself

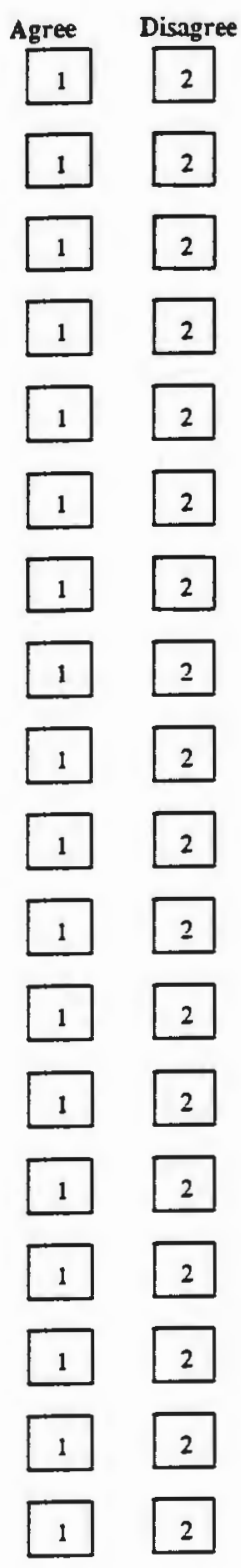




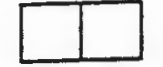

Center Number

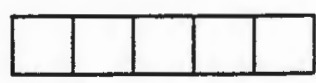

Screening Number

\begin{tabular}{|l|l|l|l|l|l|l|l|}
\hline 1 & 4 & 8 & 10 & 12 & 18 & 24 & 36 \\
\hline
\end{tabular}

Visit Month

Biris Number

105. You often feel very upset

106. People sometimes take advantage of you

107. Your life is good

108. A home should be spotless

109. You are easily upset by your problems

110. You never listen to gossip

111. Your parents did not understand you

112. Many things in life make you angry

113. Yout child has special problems

114. You do not like most children

115. Children should be seen and not heard

116. Most children are alike

117. It is important for children to read

118. You are often depressed

119. Children should occasionally be thoughtful of their parents

120. You are often upset

121. People don't get along with you

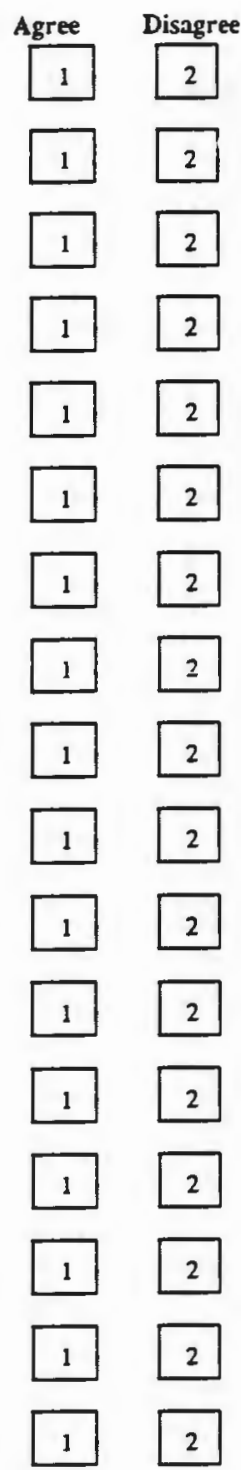




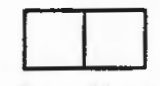

Center Number

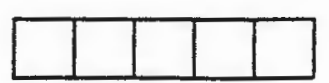

Screeging Number

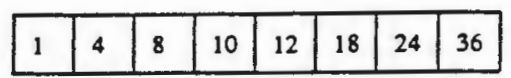

Visit Month
Birtb Number

122. A good child keeps his toys and clothes aeat and orderly

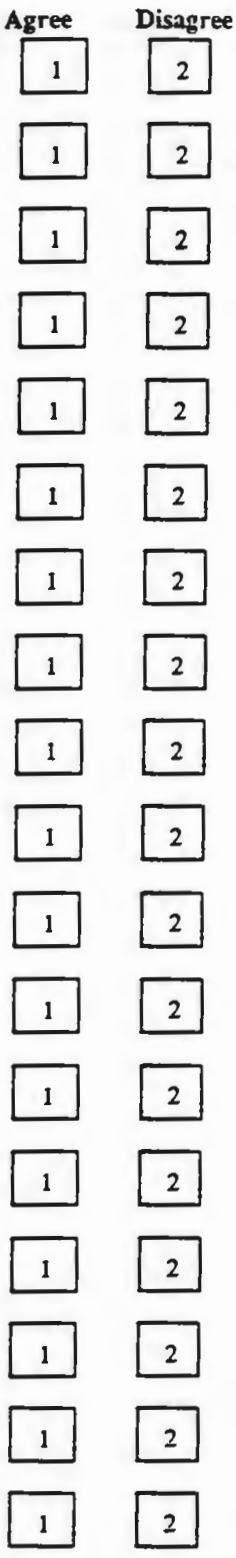

123. Children sbould always make their parents happy

124. It is natural for a child to sometimes ulk back

125. You are never unfair to others

126. Occesionally, you enjoy not baving to take care of your child

127. Children should aiways be neat

128. You have a child who is slow

129. A parent must use punishment if be wants to control a child's bebavior

130. Children sbould never cause trouble

131. You usually punisb your child when be/she is crying

132. A child peeds very strict rules

133. Children should never go against their parents" orders

134. You often feel better than others

135. Children sometimes get on your nerves

136. As a child you were often afraid

137. Children sbould always be quiet and polite

138. You are often upset and do not know why

139. Your daily work upsets you 
FORM NC62.1

$2 / 15 / 94$

Page 9 of 10
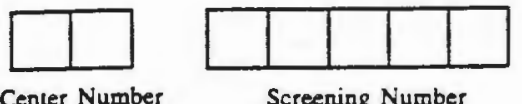

Screening Number

\begin{tabular}{|l|l|l|l|l|l|l|l|}
\hline 1 & 4 & 8 & 10 & 12 & 18 & 24 & 36 \\
\hline
\end{tabular}

Visit Montb

Birth Number
140. You sometimes fear that your children will not love you

145. You often feel alone

146. You sometimes say bad words

147. Right now, you are deeply io love

148. Your family bas many problems

149. You never do anything that is bad for your bealth

150. You are always happy with what you bave

151. Other people bave made your life hard

152. You laugh some almost every day

153. You sometimes worry that your needs will not be met

154. You ofiea feel afraid

155. You sometimes get silly

156. A person should keep bis business to himself

157. You never raise your voice in anger

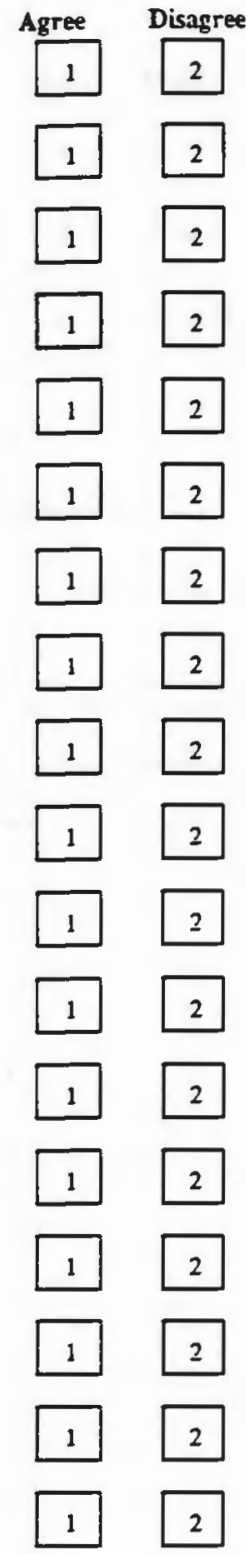




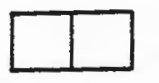

Center Number

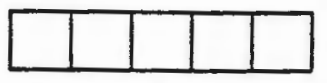

Screening Number

\begin{tabular}{|l|l|l|l|l|l|l|l|}
\hline 1 & 4 & 8 & 10 & 12 & 18 & 24 & 36 \\
\hline
\end{tabular}

Visit Month
Page 10 of 10

Birb Number

158. As a child you were bocked around by your pareats

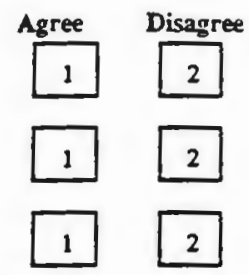

159. You sometimes think of yourself before others

2

160. You always tell the truth

2

Interviewe: Response:

161. Rate bow confident you foel that information repored on this form is reliable and truthful.
Not Confideat
1
Somewhat Confident
2
Very Confident
3

Form completed by:

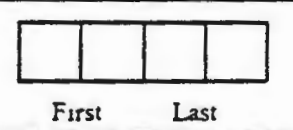

Date form completed:

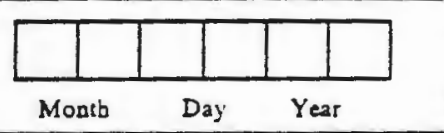


Appendix E

MLS form for BDI 

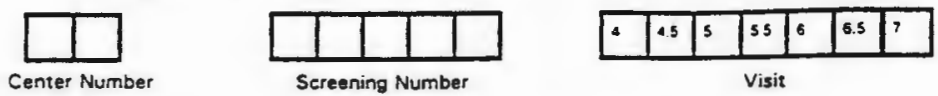

$$
\text { Visit }
$$

\section{BECK INVENTORY (BDI) - INTERVIEWER RESPONSE}

A. Interviewer Preliminary Text and Response

Interviewer: Read this statement to the respondent prior to their attempting this questionnaire

-This questionnaire has to do with your own feelings. On the questionnaire are groups of statements. Read the group of statements in each question; then pick out the one statement in that group which best describes the way you have been feeling this past week, including today. The statements refer to feelings in general--not just about being a parent, but generally. Check the number to the left of the statements that corresponds to your feelings. I will go over the first questions with you to make sure you understand the procedure. Please read the first group of statements and tell me which number you would choose. Would it be easier if I read the statements and you marked the form? Remember these are statements about your feelings.)-

Interviewer Response:

1. Relationship Code of respondent

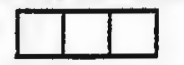

2. Record how this questionnaire was administered to the respondent

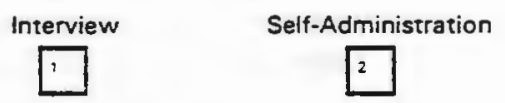

2a. If Interview, rate how confident you feel that information reported on this form is reliable and truthful

Not Confident Somewhat Confident Very Confident
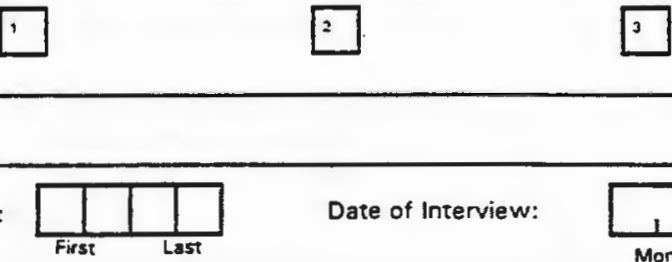

Date of Interview:

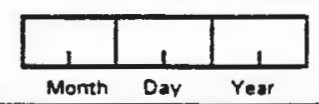



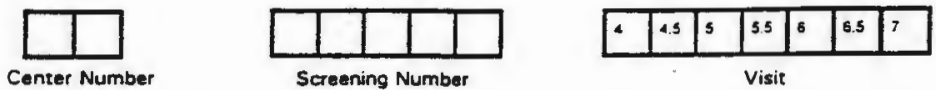

BECK INVENTORY (BDI)

Interview or Self-Assessment

1.

I do not feel sad.

I feel sad.

I am sad all the time and I can't snap out of it.

I am so sad or unhappy that I can't stand it.

2

I am not particularly discouraged about the future.

I feel discouraged about the future.

I feel I have nothing to look forward to.

I feel that the future is hopeless and that things cannot improve.

3.

I do not feel like a failure.

I feel I have failed more than the average person.

As I look back on my life, all I can see is a lot of failures.

I feel I am a complete failure as a person.

4. I get as much satisfaction out of things as I used to.

I don't enjoy things the way I used to.

I don't get real satisfaction out of anything any more.

I am dissatisfied or bored with everything.

5. 1 I don't feel particularly guilty.

I feel guilty a good part of the time.

I feel quite guilty most of the time.

I feel guilty all of the time.

6. 1 I don't feel I am being punished.

I feel I may be punished.

I expect to be punished.

I feel I am being punished.

7. 1 I don't feel disappointed in myself.

I am disappointed in myself.

I am disgusted with myself.

I hate myself. 
8.

I don't feel I am any worse than anybody else.

I am critical of myself for my weaknesses or mistakes.

I blame myself all the time for my faults.

I blame myself for everything bad that happens.

9.

\begin{tabular}{|l|}
\hline 1 \\
\hline 2 \\
\hline 3 \\
\hline 4 \\
\hline
\end{tabular}

I don't have any thoughts of killing myself.

I have thoughts of killing myself, but I would not carry them out.

I would like to kill myself.

I would kill myself if I had the chance.

10.

I don't cry any more than usual.

I cry more now than I used to.

I cry all the time now.

I used to be able to cry, but now I can't cry even though I want to.

11. I am no more irritated now than I ever am.

2 I get annoyed or irritated more easily than I used to.

3 I feel irritated all the time now.

$4 \quad$ I don't get irritated at all by the things that used to irritate me.

12.

I have not lost interest in other people.

I am less interested in other people than I used to be.

I have lost most of my interest in other people.

I have lost all of my interest in other people.

13. I make decisions about as well as I ever could.

I put off making decisions more than I used to.

I have greater difficulty in making decisions than before.

I can't make decisions at all any more.

14. I Ion't feel I look any worse than I used to.

$2 \quad$ I am worried that I am looking old or unattractive.

3 I feel that there are permanent changes in my appearance that make me look unattractive.

4 I believe that I look ugly. 

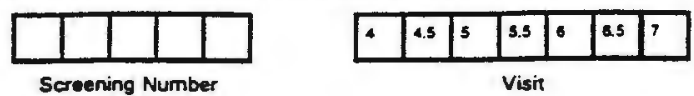

15.

I can work about as well as before.

It takes an extra effort to get started at doing something.

I have to push myself very hard to do anything.

I can't do any work at all.

16.

I can sleep as well as usual.

I don't sleep as well as I used to.

I wake up 1-2 hours earlier than usual and find it hard to get back to sleep.

I wake up several hours earlier than I used to and cannot get back to sleep.

17.

I don't get more tired than usual.

I get tired more easily than I used to.

I get tired from doing almost anything.

I am too tired to do anything.

18. 1 My appetite is no worse than usual.

My appetite is not as good as it used to be.

My appetite is much worse now.

I have no appetite at all any more.

19. I haven't lost much weight, if any, lately.

I have lost more than 5 pounds.

I have lost more than 10 pounds.

I have lost more than 15 pounds.

19 a.

I am purposely trying to lose weight by eating less.

Yes

No

20.

I am no more worried about my health than usual.

I am worried about physical problems such as aches and pains; or upset stomach; or constipation

3 I am very worried about physical problems and it's hard to think of much else.

4 I am so worried about my physical problems that I cannot think about anything else.

21. 1 I have not noticed any recent change in my interest in sex.

I am less interested in sex than 1 used to be.

I am much less interested in sex now.

I have lost interest in sex completely. 
Appendix F

MLS form for BSI 


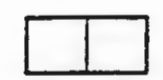

Censer Number

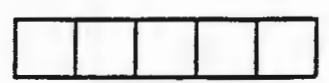

Screeaing Number

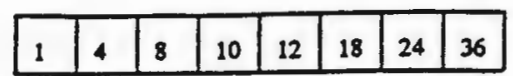

Visit Montb

\section{BRIEF SYMPTOM INVENTORY (BSI)}

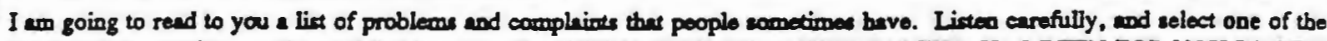
numbered descriptions on the card that bert describer HOW MUCH OF A PROBLEM THIS HAS BEEN FOR YOU DURING

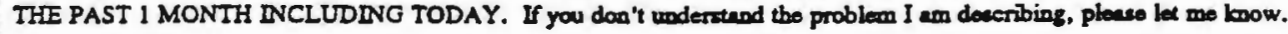

The card chould have the following scals written on it:

$\begin{array}{llll}\text { (0) (1) (3) } & \text { (3) }\end{array}$

Not At All A Litle Bit Moderately Quite \& Bit Extremely/A Whoie Lot

In the past I MONTH how much were you hathered by:

1. Feeling nervous or shaly inside

2. Foeling faint or dizry

3. The idea that someone else can control your thoughts

4. Foeling otber people are to blume for most of your troubles

5. Trouble remembering things

6. Feeling easily amoyed or irritated

7. Pains in beart or chest

8. Feeling afraid in open spaces

9. Thoughts of ending your lifo

10. Feeling that most people cannot be trusted

11. Poor appetite

12. Feeling suddenly scered for no resson

13. Temper outbursts that you could sot control

14. Feeling lonely even when you are with poople

15. Feeling blocked in getting things done

16. Feeling lonely

17. Feeling blue

$\begin{array}{lllll}0 & 1 & 2 & 3 & 4 \\ 0 & 1 & 2 & 3 & 4 \\ 0 & 1 & 2 & 3 & 4 \\ 0 & 1 & 2 & 3 & 4 \\ 0 & 1 & 2 & 3 & 4 \\ 0 & 1 & 2 & 3 & 4 \\ 0 & 1 & 2 & 3 & 4 \\ 0 & 1 & 2 & 3 & 4 \\ 0 & 1 & 2 & 3 & 4 \\ 0 & 1 & 2 & 3 & 4 \\ 0 & 1 & 2 & 3 & 4 \\ 0 & 1 & 2 & 3 & 4 \\ 0 & 1 & 2 & 3 & 4 \\ 0 & 1 & 2 & 3 & 4 \\ 0 & 1 & 2 & 3 & 4 \\ 0 & 1 & 2 & 3 & 4 \\ 0 & 1 & 2 & 3 & 4\end{array}$




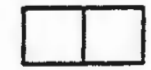

Center Number

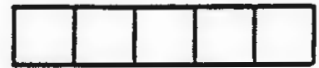

Screening Number

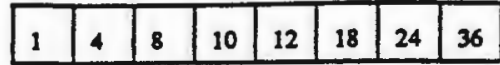

Visit Month
36

Birth Number

\begin{tabular}{|lllll}
\hline$(0)$ & $(1)$ & (2) & (3) & (1)
\end{tabular}

Not Ai All A Litle Bit Modertely

In the past $1 \mathrm{MONTH}$, hov mach suere you bothered by:

18. Feeling Do irserest in things

19. Fecling fertil

20. Your feelings being easily burt

21. Feeling that people sre unfriendly or dislike you

22. Feeling inferior to others

23. Nause or upset stomach

24. Feeling that you are watched or talked about by others

25. Trouble falling asleep

26. Having to check and double-check what you do

27. Trouble making decisions

28. Feeling afrid to trevel on buses, aubways, or trains

29. Trouble culching your breath

30. Hot or cold spells

31. Haviog to avoid certain things, places or activities becuse they frighten you

32. Your mind going blenk

33. Numbness or tingling in pars of your body

34. The idea that you should bo punisbod for your sins

35. Feeling bopeless about the funure

36. Trouble coocentrating

37. Feeling weak in parts of your body

38. Feeling tease or keyed up

39. Thoughes of deach or dying
(4)

Extremely/A Whole Lot 


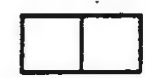

Center Number

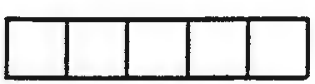

Screening Number

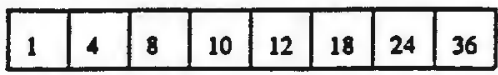

Visit Mooth
(4)

(3) Quite Bit
Extremely/A Whole Lot

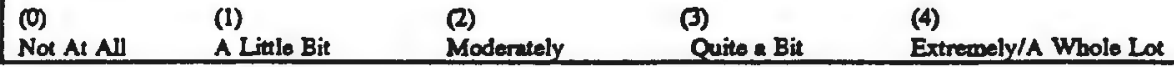

In the past 1 MONTH, how much werce yeu bathered by:

40. Having urges to beat, injure, or harm someono

41. Having urges to break or ansh things

42. Feeling very self-conscious with others

43. Feeling unensy in crowds

44. Never feeling close to another person

45. Auncks of terror or panic

46. Getting into frequent arguments

47. Feeling nervous when you aro left alono

48. Otber people not giving you credit for your achievements

49. Feeling so restless you couldn't sit still

50. Feeling worbless

$\begin{array}{lllll}0 & 1 & 2 & 3 & 4 \\ 0 & 1 & 2 & 3 & 4 \\ 0 & 1 & 2 & 3 & 4 \\ 0 & 1 & 2 & 3 & 4 \\ 0 & 1 & 2 & 3 & 4 \\ 0 & 1 & 2 & 3 & 4 \\ 0 & 1 & 2 & 3 & 4 \\ 0 & 1 & 2 & 3 & 4\end{array}$

51. Feeling that people will take advantage of you if you let them

52. Feelings of guilt

53. The ides that something is wrong with your mind

$\begin{array}{lllll}0 & 1 & 2 & 3 & 4 \\ 0 & 1 & 2 & 3 & 4 \\ 0 & 1 & 2 & 3 & 4\end{array}$

Inlerviewer Response:

54. Rate bow confident you feel that information reported on this form is reliable and truthful.

Not Confident 1
Somewhyt Confident

2
Very Confideat

3

Birh Number 
Appendix G

MLS form for MSRI 


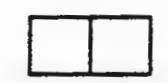

Ceover Number

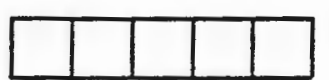

Screening Number

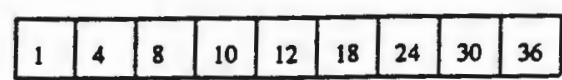

Vitit Month
36

Birth Number

\section{MATERNAL SELF-REPORT INVENTORY}

Instructions: This questionnaire is to be answered by the BIOLOGICAL MOTBER ONLY. Statements about "your baby" refer

to the baby carolled in the audy. Try to isolate the mother from others in the bowe to conduct this interview.

In this questionnatre I am gaing to read statements thot tath about feelings and atitudes that some mathers hove. Please use the $S$ point scale to choose the answer that comes the closest to how much you agree or disagree wish the statement.

\begin{tabular}{|c|c|c|c|c|}
\hline $\begin{array}{c}\text { (1) } \\
\text { Strongly Diengres }\end{array}$ & $\begin{array}{c}\text { (2) } \\
\text { Diengree }\end{array}$ & $\begin{array}{c}\text { (3) } \\
\text { Neither Agree } \\
\text { or Disagree }\end{array}$ & $\begin{array}{c}\text { (4) } \\
\text { Agroe }\end{array}$ & $\begin{array}{c}\text { (5) } \\
\text { Strongly Agree }\end{array}$ \\
\hline
\end{tabular}

1. You found the experience of habor and delivery to be ooe of the most unplecusnt experiences you've over had.

2. Yous think thrt you are a good mother.

3. You are are that you will continue to have a close and warm relationship with your baby.

4. You are not sure of your ability to help your baby learn now things.

5. Looking forward to buving a beby geve you more pleasure then acturlly having one.

6. You have real doubts sbout whether your baby is growing up normally.

7. You remember thet deliveriag your baby was very frightening and unpleasant.

8. You often worry that you may be forgetful and cause something bed to happen to your baby.

9. You sre are thet you will be able to work out any normel problems with your baby.

10. You are worried that you are not ablo to figure our what your beby needs.

11. You worry about whether or oot your baby likes you.

12. You doa't mind the things you can't do since having this baby.

13. You remember the delivery experieace as being very exciting.

14. You ere worried sbout whether or not your baby is growing up normally.

15. You doa't think that your baby can love you the way that you are. 


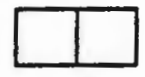

Center Number

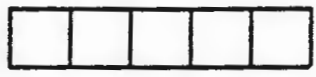

Screening Number

\begin{tabular}{|l|l|l|l|l|l|l|l|l|}
\hline 1 & 4 & 8 & 10 & 12 & 18 & 24 & 30 & 36 \\
\hline
\end{tabular}

Visit Month

Birth Number

\begin{tabular}{|cccc|}
\hline $\begin{array}{c}\text { (1) } \\
\text { Strongly Diengree }\end{array}$ & (2) & $(3)$ & $(4)$ \\
Diegree & $\begin{array}{l}\text { Neithor Agree } \\
\text { or Diengree }\end{array}$ & Agree & Strongly Agree \\
\hline
\end{tabular}

16. It really makes you feol and when you think about all there is to do as a mocher.

17. You worry that you will nok know what to do if your beby gets sick.

18. It is eary for you to know what your beby wants.

19. You remember the whole experience of labor and delivery to be ose of the beat experiences of your life.

20. You no longer are awtroned and chumsy in handling your baby.

21. You are sure that you will be sble to teach your baby new things.

22. You are sure that your beby will be atrong and beatthy.

3. You feel that you do a good job tuking cure of your baby.

24. You are not sure that you know onough to be able to teach your baby the many things whicb be/ che will have to learn.

25. You worny bour being able to take cere of your baby's emotional needs.

26. You we sure thet your baby will love you very much.

$\begin{array}{lllll}1 & 2 & 3 & 4 & 5 \\ 1 & 2 & 3 & 4 & 5 \\ 1 & 2 & 3 & 4 & 5 \\ 1 & 2 & 3 & 4 & 5 \\ 1 & 2 & 3 & 4 & 5 \\ 1 & 2 & 3 & 4 & 5 \\ 1 & 2 & 3 & 4 & 5 \\ 1 & 2 & 3 & 4 & 5 \\ 1 & 2 & 3 & 4 & 5 \\ 1 & 2 & 3 & 4 & 5\end{array}$

Interviewer Response:

27. Rete bow confident you foel that information reported on this form is reliable and enuthful.

Na Confiden

1

Somewbet Confident

2

Very Confideat

3.

Form completed by:

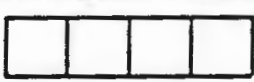

First
Date form completed:

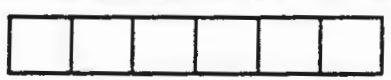

Month
Day

Year 
Appendix $\mathrm{H}$

MLS form for IBQ 


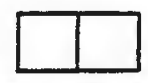

Ceoter Number

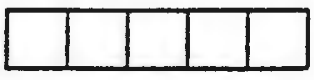

Screening Number

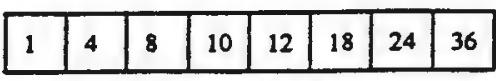

Visit Month

Birth Number

Interviewer. Ask if the carelaker has speat the last week with the baby. If yes, read the questions as they are written when referring to the "last week". If go, ask if the caretsker bas speot a recent week during the last month with the beby. If yes, replace the phrase "last week" with "the last week you spers wish the baty". Do not complete the form if the carrtaker bas not apent at least ooe week with the baby during the previous month.

I will ask you about some common situations that happen with young childnen. For excomple, did the baby have to wait for food? If you answer, yes, this happened, I will mad you some ways babies behave in that sination. For each behavior I read, please tell me how ofien your baby did this during the last week (the past seven days) by choosing one of the numbers on the card. These numbers zell me how often you saw this behavior during the last week.

(1)

Never
(2)

About Half the Time
(4)

Most of the Time Always

"Never" is used when you saw the baby in the sifuasion but the baby never behoved the way $l$ said. For axample, if the baby had to wail for food bus never eried loudly while waiting, choose (I) Never. If the baby sometimes cried loudly for food, choose (2) Some of the Time. If the baby cried loudly half the time, choose (3) About Half the Time. If the baby uswally cried loudly when waiting for food, choose (A) Most of the Time. If the baby cried loudly all the time when waiting for food, choose (5) Always.

Section A. Feeding

1. Did the baby ever bave to wait for food or liquids during the last week?

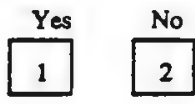

If yes, how often did the bahy?
2. cry loudly?
b. fuss a linle?
c. stay quiet (not react)?

2. Do you usually see the baby during feeding?

$\begin{array}{rrrrr}1 & 2 & 3 & 4 & 5 \\ 1 & 2 & 3 & 4 & 5 \\ 1 & 2 & 3 & 4 & 5 \\ & & & \text { Yes } & \text { No } \\ & & & 1 & 2\end{array}$

If yes, how often did the baby?
a. wave arms?
b. squirm or kick?
c. Lie or sit quietly?
d. fuss or cry when s/he had eaough to eat?

$\begin{array}{lllll}1 & 2 & 3 & 4 & 5 \\ 1 & 2 & 3 & 4 & 5 \\ 1 & 2 & 3 & 4 & 5 \\ 1 & 2 & 3 & 4 & 5\end{array}$




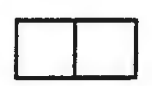

Ceater Number

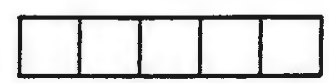

Screening Number

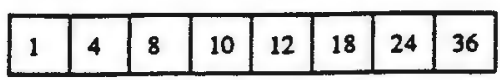

Visit Month
Birth Number

\begin{tabular}{|lllll}
\hline$(1)$ & $(2)$ & $(3)$ & $(4)$ & (5) \\
Never & Some of the Time & About Helf the Time & Most of the Time & Always \\
\hline
\end{tabular}

3. Was s/he ever given a food s/he didn't like? If yes,

2. did s/he fuss or cry when given that food?

\section{Whs s/be given a new food?}

If yes, how often did the baby:
. take it immediately?
b. reject if by spitting out, closing wouth, etc?
c. refuse it no matter how many times you tried?

Most of the Time

Always

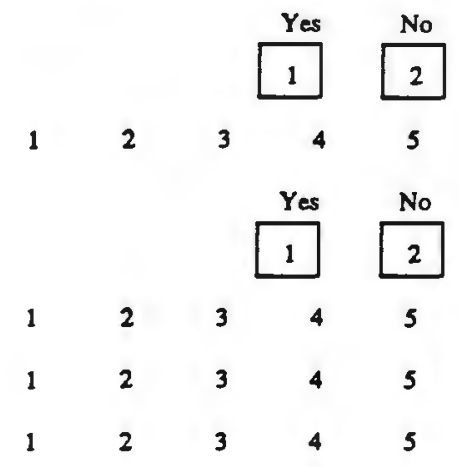

Section B. Sleeping

Where does the baby usually sieep at night?

Interviewer: Substitute caretaker's response if ather than bed in $n, 7 \mathrm{a}, 7 \mathrm{~b}, 8 \mathrm{~d}, 27,27 \mathrm{a}, 27 \mathrm{~b}$

5. Are you normally there when the baby falls asleep at night?

If yes, before falline asleep at night during the last week, how often did the baby:

$$
\text { a. fuss or cry? }
$$

6. Do you usually see the baby before going to sleep for naps?

If yes, bow ofien did the baby:

a. cry or fuss before going to sleep for axps?

7. Do you usually see the baby asleep in his/her bed at aight?

If yes, how ofien did the babv:
a. toss about in the bed?
b. move from the middle to the ead of the bed?
c. sleep in one position only? 


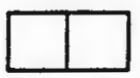

Center Number

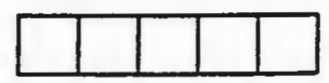

Screening Number

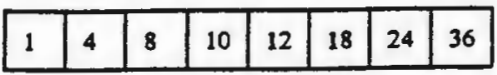

Visit Montb
Birth Number
(1)

Never
(2)

Some of the Time
(3)

About Half the Time
(4)

Most of the Time
(5)

Always

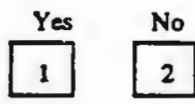

8. Are you usually there wheo the baby wakes up after sleep?

If yes,

after sleeping how often did the baby:

a. fuss or cry immediately?

b. cry if someone didn't come within a few minutes?

c. coo and talk for periods of 5 minutes or longer?

d. play quietly in bed?

$\begin{array}{lllll}1 & 2 & 3 & 4 & 5 \\ 1 & 2 & 3 & 4 & 5 \\ 1 & 2 & 3 & 4 & 5 \\ 1 & 2 & 3 & 4 & 5\end{array}$

\section{Section C. Bathing and Dressing}

9. During the last week, were you there while the baby was bathed and dressed? If yes,

when beine dressed or undressed, how often did the baby:

a. wave bis/her arms and kick?

b. squirm and/or try to roll away?

c. smile or laugh?

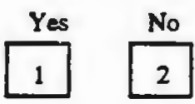

when put into the bath water. how often did the baby:

d. smile?

e. laugh?

f. splash or kick?

8. turn body ad/or squirm?

when his/her face was washed, bow often did the baby:

h. smile or laugh?

i. fuss or cry?

when his/her hair was beine washed, how often did the bubv:

j. smile or laugh?

k. fuss or cry?

\begin{tabular}{lllll} 
& & & \multicolumn{1}{c}{ Yes } & No \\
\cline { 3 - 3 } & & & & \\
1 & 2 & 3 & 4 & 5 \\
1 & 2 & 3 & 4 & 5 \\
1 & 2 & 3 & 4 & 5 \\
1 & 2 & 3 & 4 & 5 \\
1 & 2 & 3 & 4 & 5 \\
1 & 2 & 3 & 4 & 5 \\
1 & 2 & 3 & 4 & 5 \\
1 & 2 & 3 & 4 & 5 \\
1 & 2 & 3 & 4 & 5 \\
1 & 2 & 3 & 4 & 5 \\
1 & 2 & 3 & 4 & 5
\end{tabular}




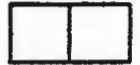

Center Number

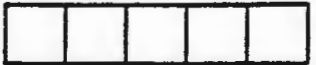

Screening Number

\section{\begin{tabular}{|l|l|l|l|l|l|l|l|}
\hline 1 & 4 & 8 & 10 & 12 & 18 & 24 & 36 \\
\hline
\end{tabular}}

Visit Month
Birth Number
(1) Never
(2) Some of the Time
(3) About Half the Time
(4) Most of the Time
(5) Aways

Section D. Play

10. During the lass week, did you see the baby look at picures in books ind/or magarines? If yes, how often did the bahy look at them:
a for 5 minutes or longer at a time?
b. for a few minutes at a time but not as long as 5 minutes?

11. During the last week, did you see the baby stare at a mobile, crib bumper, or picture? If yes, how often did the baby stare at it for:

$$
\text { 2. } 5 \text { minutes or longer? }
$$

12. During the last week, did you see the baby play with a toy or object? If yes, how ofien did the haby:

a. play with it for 10 minutes or longer?

b. play with it for 5-10 minutes but not for more thas 10 minutes?

c. Spend time just looking at playthings but not holding or wuching them?

d. repeat the same movement with an object for 2 minutes or longer (e.g. putting a block in a cup, kicking or bitking a mobile)?

13. Duriag the last week, did you watch the baby play or play with bim or ber yourself? If yes, how often did the baby:
a. repeat the same sounds over and over again?

b. laugh sloud during play?

14. Did something the baby was playing with have to be takeo away? If yes, how ofien did s/he:
2. cry or show distress for more than 3 minutes?
b. ery or show distress but not longer than 3 minutes?
c. not care?

\begin{tabular}{|c|c|c|c|c|}
\hline \multirow[b]{2}{*}{ ines? } & & & Yes & No \\
\hline & & & 1 & 2 \\
\hline 1 & 2 & 3 & 4 & 5 \\
\hline 1 & 2 & 3 & 4 & 5 \\
\hline & & & Yes & No \\
\hline re? & & & 1 & 2 \\
\hline 1 & 2 & 3 & 4 & 5 \\
\hline & & & Yes & No \\
\hline & & & 1 & 2 \\
\hline 1 & 2 & 3 & 4 & 5 \\
\hline 1 & 2 & 3 & 4 & 5 \\
\hline 1 & 2 & 3 & 4 & 5 \\
\hline 1 & 2 & 3 & 4 & 5 \\
\hline & & & Yes & No \\
\hline & & & 1 & 2 \\
\hline 1 & 2 & 3 & 4 & 5 \\
\hline 1 & 2 & 3 & 4 & 5 \\
\hline & & & Yes & No \\
\hline & & & 1 & 2 \\
\hline 1 & 2 & 3 & 4 & 5 \\
\hline 1 & 2 & 3 & 4 & 5 \\
\hline 1 & 2 & 3 & 4 & 5 \\
\hline
\end{tabular}



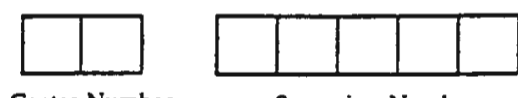

\begin{tabular}{|l|l|l|l|l|l|l|l|}
\hline 1 & 4 & 8 & 10 & 12 & 18 & 24 & 36 \\
\hline \multicolumn{6}{|c|}{ Visit Mouth }
\end{tabular}

Birth Number

(1) Never

(2) Some of the Time

(3) About Half the Time

(4) Most of the Time

(5) Nways

15. Did you the baby tickled is the last week? If yes, how often did the baby:

a. smile or iaugh when tickled?

b. cry or show distress when tickled?

16. Did you see the baby tossed around playfully in the last week? If yes, bow ofien did the babv:
a. smile?
b. Laugh?

17. Did the baby play peek-a-boo during the last week?

If yes, bow ofien did the babv:
a. smile?
b. laugh?

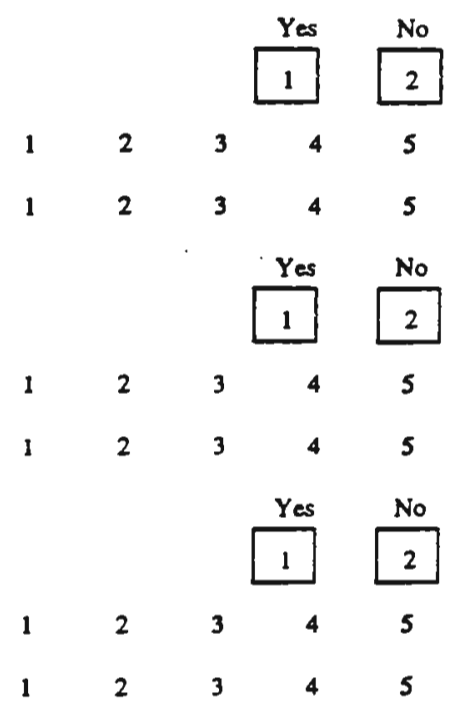

Section E. Daily Activities

18. In the last week, did you ever see the baby respond to a loud sound (blender, car backfires, vacuum cleaner, etc)? If yes, bow ofien did the baby: 2. cry or show distress?
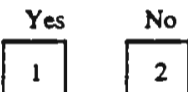

19. Did the baby see a change in a parent or caregiver's appearance (new glasses, face cream, new hair style)?

If yes, how ofien did s/he:

$$
\text { a. cry or show distress? }
$$

20. During the last week, did you see the baby watch TV?

If yes, how ofien did she:
a. look at it for 5 minutes or more at a time?
b. look at it but not as long as 5 minutes? 


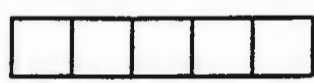

Screeaing Number

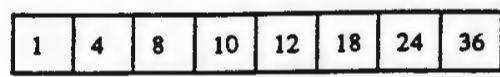

Visit Month
Birth Number
(1)

Never

(2)

Some of the Time

(3)

About Half the Time

(4)

Most of the Time

Aways

21. During the last week, have you seen the baby startle (gasp, throw out arms)? If yes, how often did the baby:

2. cry afier being sertled by something?

22. Duriag the last week, did you bold the baby?

If yes, how offen did s/he:

.. squirm, pull away or kick?

23. During the last week, did you see the baby placed on his/her back?

If yes, how often did sihe:
a. fuss or protest?
b. smile or laugh?
c. Lie still?
d. wave arms and kick?
e. squirm and/or nuro body?

24. During the last week, did you see the baby want something?

If yes, how often did s/he:

a. become upset when s/he could not get what s/he wanted?

b. have cantrums (crying, screaming, face red, etc.) when s/be did not get what s/be wanted?

25. During the last week, was the baby piaced in an infant seat or ar seat? If yes, how often did the baby:
a. wave arms and kick?
b. squirm and turn body?
c. show distress at first, then quiet down?
d. lie or sit quietly?

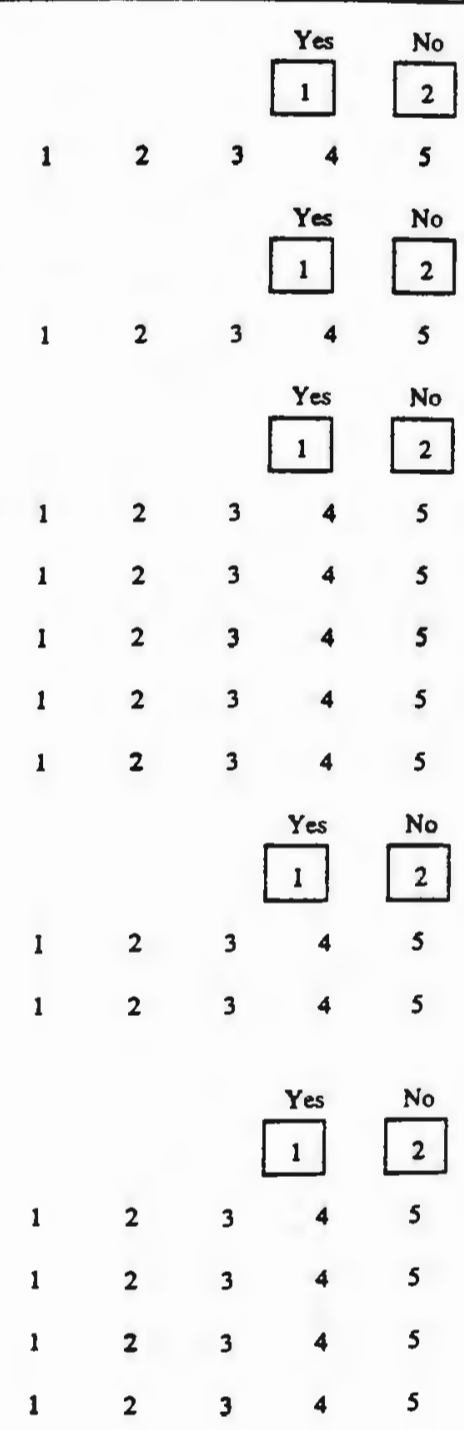




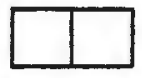

Center Number

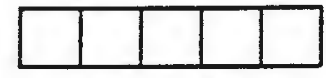

Screening Number

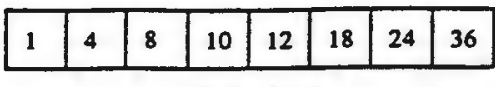

Visit Month
Birb Number
(1)

Never

(2)

Some of the Time

(3) About Half the Time

(4) Most of the Time

(5)

26. Was the baby placed in other confining places (play pen. swing, etc.)? If yes, how often did the baby:

. protest (or become upset)?

27. During the Last week, did you ever leave the baby in the bed when $s /$ he was awake (night/nap)?

If yes, how often did sthe:

2. secm agry (crying and fussing) when you lefi ber/him in the bed?

b. seem contenced when left in the bed?

28. During the last week, were you ever away from the baby and then returned when s/he was awake? If yes, when you came back, how often did s/he: a. smile or laugh?

29. During the last week, did the baby meet a new or unfamiliar person (store clerk, clinic aurse. friend, family member they baven' $t$ seen before)? If yes, how ofien did the baby:
a. cling to a parent or caregiver?
b. refuse 10 go to the stranger?
c. keep a distance from the stranger?
d. never act friendly or "warm up" to the stranger?
e. approach the stranger at once?
f. smile or laugb?

30. During the last week, was the baby istroduced to a dog or cat? If yes, how often did the babv:
a. cry or show distress?
b. smile or laugb?
c. appraach at once?

12

3

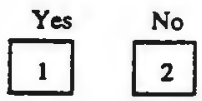

345

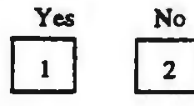

45

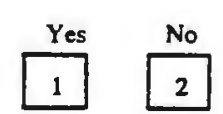

45

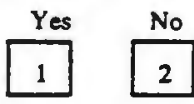

$\begin{array}{lllll}1 & 2 & 3 & 4 & 5\end{array}$

$\begin{array}{lllll}1 & 2 & 3 & 4 & 5\end{array}$

$\begin{array}{lllll}1 & 2 & 3 & 4 & 5\end{array}$

$\begin{array}{lllll}1 & 2 & 3 & 4 & 5\end{array}$

$\begin{array}{lllll}1 & 2 & 3 & 4 & 5\end{array}$

$\begin{array}{lllll}1 & 2 & 3 & 4 & 5\end{array}$

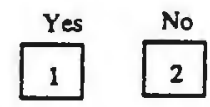

$\begin{array}{lllll}1 & 2 & 3 & 4 & 5 \\ 1 & 2 & 3 & 4 & 5 \\ 1 & 2 & 3 & 4 & 5\end{array}$




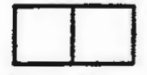

Ceater Number

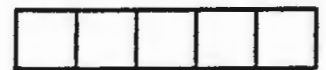

Screening Number

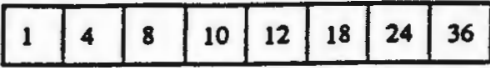

Visit Moath

Birth Number

\begin{tabular}{|llll}
\hline (1) & (2) & (3) & (4) \\
Never & Some of the Time & About Half the Time & Most of the Time
\end{tabular}

Section F. Soothing Techniques

31. Heve you tried eny of the following soothing techniques in the last two weeks (or in a receat two week period)? If yes, how often did the method soothe the baby?

a. rocking

b. holding

c. ringing or talking

d. walking with the baby

e. giving the baby a toy

f. showing the baby something to look at

g. patting or gently rubbing some part of the baby's body

b. offering something to eat or drink

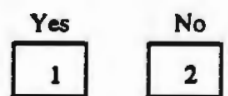

If yes,

2

3

5
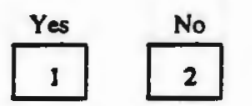

If yes,

Yes

\begin{tabular}{|l|} 
No \\
\hline 2 \\
\hline
\end{tabular}

If yes

2

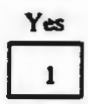

No

If yes,

Yes

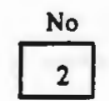

If yes,

234

Yes
1

\begin{tabular}{c} 
No \\
\hline 2 \\
\hline
\end{tabular}

If yes,

2

Yes
1

No

If yes,

\begin{tabular}{c} 
Yes \\
\hline 1
\end{tabular}

\begin{tabular}{c} 
No \\
\hline 2 \\
\hline
\end{tabular}

If yes, 


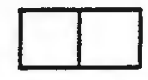

Center Number

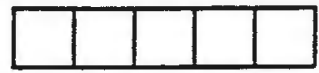

Screening Number

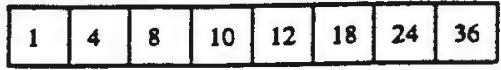

Visit Mouth

\section{6}

Birtb Number (1)
Never
(2)

Some of the Time
(3) About Half the Time
(4) Most of the Time
(5) Nways i. offering baby his/her security object (special woy like a blanket or doll)

j. changing baby's position

k. ober (please specify)
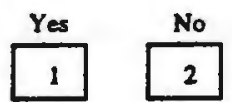

If yes,
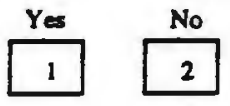

If yes,

No

$\begin{array}{r}\text { Yes } \\ \hline 1\end{array}$

\section{2}

If yes

1

35

Lnterviewer Respoose:

32. Rate bow confident you fel that information reported on this form is reliable and truthful.

Not Confident

1
Somewhat Confident

2
Very Confident

3

Form completed by:

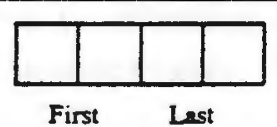

Date form complesed:

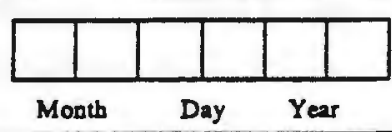




\section{Bibliography}

Abidin, R. (1983). The Parenting Stress Index - Manual. Virginia: Pediatric Psychology Press.

Ainsworth, M. (1984). Attachment. In N. Endler \& J. McV. Hunt (Eds.), Personality and the Behavioral Disorders, 1. New York: Wiley.

Ainsworth, M., Blehar, M., Waters, E., \& Wall, S. (1978). Patterns of attachment: A psychological study of the strange situation. Hillsdale, NJ: Erlbaum.

Ainsworth, M., \& Witting, B. (1969). Attachment and exploratory behavior of one-year-olds in a strange situation. In B. Foss (Ed.), Determinants of Infant Behavior. London: Methuen.

Baldwin, W., \& Cain, V. (1980). The children of teenage parents. Family Planning Perspectives, $12,34-43$.

Barratt, M., \& Roach, M. (1995). Early interactive processes: Parenting by adolescent and adult single mothers. Infant Behavior and Development, 18, 97-109.

Beck, A., Steer, R., \& Garbin, M. (1988). Psychometric properties of the beck depression inventory: Twenty five years of evaluation. Clinical Psychology Review, 8, $77-100$.

Beck, A., Ward, C., Mendelson, M., Mock, J., \& Erbaugh, J. (1961). An inventory for measuring depression. Archives of General Psychiatry, 4, 561-571.

Becker, P. (1987). Sensitivity to infant development and behavior: A comparison of adolescent and adult single mothers. Research in Nursing Health, 10, 119-127.

Belsky, J., Rovine, M., \& Taylor, D. (1984). The Pennsylvania Infant and Family Development Project, 3: The origins of individual differences in infant-mother attachment: Maternal and infant contributions. Child Development, 55, 718-728. Books.

Bowlby, J. (1969). Attachment and loss: Vol. 1. Attachment. New York: Basic

Broussard, E. (1995). Infant attachment in a sample of adolescent mothers. Child Psychiatry and Human Development, 25, 211-219.

Caldwell, B., \& Bradley, R. (1984). Administration manual (revised edition): Home observation for measurement of the environment. Little Rock: University of Arkansas. 
Cicchetti, D. (1987). Developmental psychopathology in infancy: Illustration from the study of maltreated youngsters. Journal of Consulting and Clinical Psychology, $\underline{55}, 837-845$.

Cohen, J. (1988). Statistical Power Analysis: A computer program. New York.

Crittenden, P. (1985). Maltreated infants: Vulnerability and resilience. Journal of Child Psychology and Psychiatry, 26, 85-96.

Culp, R., Appelbaum, M., Osofsky, J., \& Levy, J. (1988). Adolescent and older mothers: Comparison between prenatal maternal variables and newborn interaction measures. Infant Behavior and Development, 11, 353-362.

DeLissovoy, V. (1973). Child care by adolescent parents. Children Today, 35, $22-25$.

Desrogatis, L. (1993). Brief Symptom Inventory (BSI): Administration, Scoring, and Procedures Manual, Third Edition. Minneapolis, MN: National Computer Systems, Inc.

Egeland, B., \& Farber, E. (1984). Infant-mother attachment: Factors related to its development and changes over time. Child Development, 55, 753-771.

Egeland, B., \& Sroufe, L. A. (1981). Attachment and early maltreatment. Child Development, 52, 44-52.

Elster, A., McAnarney, E., \& Lamb, M. (1983). Parental behavior of adolescent mothers. Pediatrics, 71, 494-503.

Erickson, M., Sroufe, A., \& Egeland, B. (1985). The relationship between quality of attachment and behavior problems in a preschool high risk sample. In I. Bretherton \& E. Waters (Eds.), Growing points of attachment theory and research. Monographs of the Society for Research in Child Development, 50 (1-2, Serial No. 209).

Field, T. (1980). Interactions of preterm and term infants with their lower and middle class teenage and adult mothers. In T. Field, S. Goldberg, D. Stern, \& A. Sostek (Eds.), High Risk Infants and Children: Adult and Peer Interactions. New York: Academic.

Field, T., Widmayer, S., Stringer, S., \& Ignatoff, E. (1980). Teenage, lower class, black mothers and their pre-term infants: An intervention and developmental follow-up. Child Development, 51, 426-436. 
Flanagan, P. (1998). Teen mothers: Countering the myths of dysfunction and developmental disruption. In C. Garcia Coll, J. Surrey, (Eds.), Mothering Against the Odds: Diverse Voices of Contemporary Mothers. New York: Guilford.

Flanagan, P., Coppa, D., Riggs, S., \& Alario, A. (1994). Communication behaviors of infants of teen mothers: An exploratory study. Journal of Adolescent Health, 15, 169-175.

Flanagan, P., Garcia Coll, C., Andreozzi, L., \& Riggs, S. (1995). Predicting maltreatment of children of teenage mothers. Archives of Pediatric Adolescent Medicine, $\underline{149}, 451-455$.

Frodi, A., Grolnick, W., Bridges, L., \& Berko, J. (1990). Infants of adolescent and adult mothers: Two indices of socioemotional development. Adolescence, 98, 363374.

Furstenberg, F., Brooks-Gunn, J., \& Morgan, S. (1987). Adolescent mothers and their children later in life. Family Planning Perspectives, 19, 142-151.

Garcia Coll, C., Hoffman, J., \& Oh, W. (1987). The social ecology and early parenting of caucasian adolescent mothers. Child Development, 58, 955-963.

Garcia Coll, C., Vohr, B., Hoffman, J., \& Oh, W. (1986). Maternal and environmental factors affecting developmental outcome of infants of adolescent mothers. Developmental and Behavioral Pediatrics, 7, 230-236.

Grossmann, K., Grossmann, K., Spangler, G., Suess, G., \& Unzner, L. (1985). Maternal sensitivity and newborn's orientation responses as related to quality of attachment in northern Germany. In I. Bretherton \& E. Waters (Eds.), Growing points of attachment theory and research. Monographs of the Society for Research in Child Development, 50 (1-2, Serial No. 209).

Harwood, R. \& Miller, J. (1991). Perceptions of attachment behavior: A comparison of anglo and puerto rican mothers. Merrill Palmer Quarterly, 37, 583-599.

Harwood, R., Miller, J., \& Irizarry, N. (1995). Culture and Attachment: Perceptions of the Child in Context. New York: Guilford.

Hollingshead, A. (1975). Four Factor Index of Social Status. New Haven, CT: Yale University, Department of Sociology.

Hubbs-Tait, L., Osofsky, J., Hann, D., \& Culp, A. (1994). Predicting behavior problems and social competence in children of adolescent mothers. Family Relations, 43 , 439-446. 
Hurlbut, N., Culp, A., Jambunathan, S., \& Butler, P. (1997). Adolescent mother's self esteem and role identity and their relationship to parenting skills knowledge. Adolescence, 32, 639-655.

Jones, F., Green, V., \& Krauss, D. (1980). Maternal responsiveness of primiparous mothers during the postpartum period: Age differences. Pediatrics, 65, 579584.

Lamb, M., Hopps, K., \& Elster, A. (1987). Strange situation behavior of infants with adolescent mothers. Infant Behavior and Development, 10, 39-48.

Lamb, M., Thompson, R., Gardner, W., \& Charnov, E. (Eds.). (1985). InfantMother Attachment: The Origins and Developmental Significance of Individual Differences in Strange Situation Behavior. New Jersey: Erlbaum.

Lawrence, R., McAnarney, E., Aten, M., Iker, H., Baldwin, C., \& Baldwin, A. (1981). Aggressive behaviors in young mothers: Markers of future morbidity? Pediatric Research, 15, 443.

Levine, L., Garcia Coll, C., \& Oh, W. (1985). Determinants of mother-infant interaction in adolescent mothers. Pediatrics, 75, 23-29.

Main, M., \& Cassidy, J. (1988). Categories of response to reunion with the parent at age six: Predictable from infant attachment classification and stable over a onemonth period. Developmental Psychology, 24, 415-426.

Main, M., \& Solomon, J. (1990). Procedures for identifying infants as disorganized-disoriented during the Ainsworth Strange Situation. In M. Greenberg, D. Cicchetti, \& E.M. Cummings (Eds.), Attachment in the preschool years: Theory, research, and intervention (pp. 121-160). Chicago: University of Chicago Press.

McAnarney, E., Lawrence, R., \& Atens, M. (1979). Premature parenthood a preliminary report of adolescent mothers and behavioral characteristics of their first born infants. Pediatric Research, 13, 328.

McCullough, M., \& Scherman, A. (1991). Adolescent pregnancy: Contributing factors and strategies for prevention. Adolescence, 26, 809-816.

Miller, S. (1984). The relationship between adolescent childbearing and child maltreatment. Child Welfare, 63, 553-557.

Milner, J. (1980). The Child Abuse Potential Inventory manual (second edition). Illinois: Psytec. 
Parks, P., \& Arndt, E. (1990). Differences between adolescent and adult mothers of infants. Journal of Adolescent Health Care, 11, 248-253.

Radke-Yarrow, M., Cummings, E., Kuczynski, L., \& Chapman, M. (1985). Patterns of attachment in two and three year olds in normal families and families with parental depression. Child Development, 56, 884-893.

Ragozin, A., Basham, R., Crnic, K., Greenberg, M., \& Robinson, N. (1982). Effects of maternal age on parenting role. Developmental Psychology 18 , 627-634.

Rauch-Elnekave, H. (1994). Teenage motherhood: its relationship to undetected learning problems. Adolescence, 29, 91-104.

Roosa, M., Fitzgerald, H., \& Carlson, N. (1982). Teenage parenting and child development: A literature review. Infant Mental Health Journal, 3, 4-18.

Roosa, M, \& Vaughan, L. (1984). A comparison of teenage and older mothers with preschool children. Family Relations, 33, 259-265.

Rothbart, M. (1981). Measurement of temperament in infancy. Child Development, 52, 569-578.

Sandler, H., Vietze, P., \& O'Connor, S. (1981). Obstetric and neonatal outcomes following intervention with pregnant teenagers. In K. Scott, T. Field, \& E. Robertson (Eds.), Teenage parents and their offspring. New York: Grune \& Stratton.

Schneider_Rosen, K., \& Cicchetti, D. (1984). The relationship between affect and cognition in maltreated infants: Quality of attachment and the development of visual self recognition. Child Development, 55, 648-658.

Seifer, R., \& Dickstein, S. (1993). Parental mental illness and infant development. In C. Zeanah (Ed.), Handbook of Infant Mental Health (pp. 120-142). New York: Guilford.

Seifer, R., Sameroff, A., Dickstein, S., Keitner, G., Miller, I., Rasmussen, S., \& Hayden, L. (1996). Parental psychopathology, multiple contextual risks, and one year outcomes in children. Journal of Clinical Child Psychology, 25, 423-435.

Seifer, R., \& Schiller, M. (1995). The role of parenting sensitivity, infant temperament, and dyadic interaction in attachment theory and assessment. In E. Waters, B. E. Vaughn, G. Posada, \& K. Kondo-Ikemura (Eds.), Caregiving, cultural, and cognitive perspectives on secure base behavior and working models: New growing points of attachment theory and research. Monographs of the Society for Research in Child Development, 60 (Serial No. 244, pp. 146-174). 
Shapiro, J. \& Mangelsdorf, S. (1994). The determinants of parenting competence in adolescent mothers. Journal of Youth and Adolescence, 23, 621-642.

Shea \& Tronick, E. (1984). The Maternal Self-Report Inventory: A research and clinical instrument for assessing maternal self esteem. In H. Fitzgerald, B. Lester, \& M. Yogman, (Eds.), Theory and Research in Behavioral Pediatrics. Boston: Plenum.

Spieker, S., \& Booth, C. (1988). Maternal antecedents of attachment quality. In J. Belsky \& T. Nezworski (Eds.), Clinical implications of attachment (pp. 300-323). Hillsdale, NJ: Erlbaum.

Teti, D., Gelfand, D., Messinger, D., \& Isabella, R. (1995). Maternal depression and the quality of early attachment: An examination of infants, preschoolers, and their mothers. Developmental Psychology, 31, 364-376.

Thompson, R., Lamb, M., \& Estes, D. (1982). Stability of infant-mother attachment and its relationship to changing life circumstances in an unselected middle class sample. Child Development, 53, 144-148.

Tronick, E. Z., Ricks, M., \& Cohn, J. (1982). Maternal and infant affective exchange: Patterns of adaptation. In T. Field \& A. Fogel (Eds.), Emotion and Early Interaction. Hillsdale, NJ: Erlbaum.

Turner, P. (1991). Relationship between attachment, gender, and behavior with peers in preschoolers. Child Development, 62, 1475-1488.

Van Ijzendoorn, M., Goldberg, S., Kroonenberg, P., \& Frenkel, O. (1992). The relative effects of maternal and child problems on the quality of attachment: A metaanalysis of attachment in clinical samples. Child Development, 63, 840-858.

Van Ijzendoorn, M., \& Kroonenberg, P. (1988). Cross cultural patterns of attachment: A meta-analysis of the strange situation. Child Development, 59, 147-156.

Vaughn, B., Egeland, B., Sroufe, L. A., \& Waters, E. (1979). Individual differences in infant-mother attachment at twelve and eighteen months: Stability and change in families under stress. Child Development, 50, 971-975.

Vaughn, B., Lefever, G., Seifer, R., \& Barglow, P. (1989). Attachment behavior, attachment security, and temperament during infancy. Child Development, 60, 728-737.

Vaughn, B., Stevenson-Hinde, J., Waters, E., Kotsaftis, A., Lefever, G., Shouldice, A., Trudel, M., \& Belsky, J. (1992). Attachment security and temperament in infancy and early childhood: Some conceptual clarifications. Developmental Psychology, 28, 463-473. 
Ward, M., \& Carlson, E. (1995). Associations among adult attachment representations, maternal sensitivity, and infant mother attachment in a sample of adolescent mothers. Child Development, 66, 69-79.

Waters, E. (1978). The reliability and stability of individual differences in infantmother attachment. Child Development, 49, 483-494.

Whitman, T., Borkowski, J., Schellenbach, C., \& Nath, P. (1987). Predicting and understanding developmental delay of children of adolescent mothers: A multidimensional approach. American Journal of Mental Deficiency, 92, 40-56.

Zuravin, S. (1988). Child maltreatment and teenage first births: A relationship mediated by chronic sociodemographic stress? American Journal of Orthopsychiatry, 58, 91-103. 